\title{
What evidence exists on the impact of specific ecosystem components and functions on infectious diseases? A systematic map
}

Léa Lugassy ${ }^{1 *}\left(\mathbb{0}\right.$, Ludivine Amdouni-Boursier ${ }^{1}$, Haoues Alout ${ }^{2}$, Romuald Berrebi ${ }^{3}$, Christophe Boëte $^{2}$,

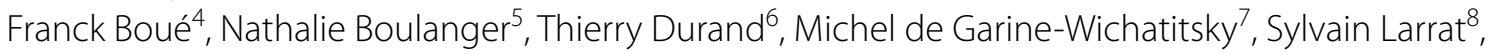
Marie Moinet ${ }^{9}$, Catherine Moulia ${ }^{2}$, Nonito Pagès ${ }^{10}$, Olivier Plantard ${ }^{11}$, Vincent Robert ${ }^{12}$ and Barbara Livoreil ${ }^{1}$

\begin{abstract}
Background: The control and prevention of vector-borne and zoonotic diseases is often based on the reduction of host or vector populations, involving but not limited to preventative culling and use of insecticides. Yet, destructive interventions such as these have shown several limitations including ineffectiveness on arthropods and negative impacts on ecosystems. An alternative strategy would be to rely on the natural ecosystem functions and their careful management to regulate such diseases. The goal of our work was to evaluate existing scientific evidence on potential links between ecosystem components/functions and 14 vector-borne and zoonotic diseases impacting human health and answer the question: "What evidence exists on the impact of specific ecosystem components and functions on infectious diseases?".

Methods: We searched for scientific articles published in English and French and screened them in a 3-round process (title, abstract and full-text). Articles were retained, without any geographical limitation, if they matched the following eligibility criteria: an exposure/intervention linked to changes in biological communities, habitats, or landscapes; an outcome consisting of any measure of infection in vector, animal or human hosts; and the presence of a comparator, in time and/or in space. The results are presented as a systematic map, followed by a narrative review where the amount of papers allowed for synthesis.

Results: Searches in 5 scientific publication databases allowed to retrieve 9723 unique articles, among which 207 were retained after the screening process. The amount of relevant literature was highly variable depending on diseases, and the types of exposures also varied greatly among studies focusing on the same disease. A hundred articles presented in the map were unique in their "disease x exposure" combination and thus not eligible for further narrative description. The remaining 107 articles were organized in 34 "disease x exposure" groups, encompassing 9 out of the 14 initial diseases. The groups were composed of 2 to 16 articles and were examined to provide a description of the current state of knowledge for those diseases.
\end{abstract}

Conclusion: Studies investigating the interaction between infectious diseases and ecosystems components and functions are still very scarce, and certain diseases are much more studied than others. Out of 14 diseases, 8

\footnotetext{
*Correspondence: lea.lugassy0@gmail.com

${ }^{1}$ Fondation Pour La Recherche Sur La Biodiversité, Paris, France

Full list of author information is available at the end of the article
}

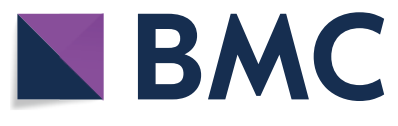

(c) The Author(s) 2021. This article is licensed under a Creative Commons Attribution 4.0 International License, which permits use, sharing, adaptation, distribution and reproduction in any medium or format, as long as you give appropriate credit to the original author(s) and the source, provide a link to the Creative Commons licence, and indicate if changes were made. The images or other third party material in this article are included in the article's Creative Commons licence, unless indicated otherwise in a credit line to the material. If material is not included in the article's Creative Commons licence and your intended use is not permitted by statutory regulation or exceeds the permitted use, you will need to obtain permission directly from the copyright holder. To view a copy of this licence, visit http://creativeco mmons.org/licenses/by/4.0/. The Creative Commons Public Domain Dedication waiver (http://creativecommons.org/publicdomain/ zero/1.0/) applies to the data made available in this article, unless otherwise stated in a credit line to the data. 
generated less than 10 relevant articles, while 2 diseases (Lyme disease and West Nile disease) represented 44\% of all relevant studies. Although several vector-borne diseases included in the review represent a major health issue in the world, such as malaria or dengue, they have been exclusively studied under the prism of land-use, and we were unable to find relevant studies that tested the regulatory role of animal biodiversity-related functions. The role of predation in the regulation of vector and host populations has rarely been studied, with the exception of schistosomiasis. The dilution and amplification effects were addressed in several studies focusing on the composition of ecological communities. This map is a first step and could be upgraded in order to guide future research projects with the aim to conduct meta-analysis and build a robust evidence base to inform decision-making.

Keywords: Biodiversity, Ecosystem services, Landscape, Dilution effect, One Health, Ecological control

\section{Background}

About $60 \%$ of all infectious diseases infecting humans are zoonotic, meaning they also infect wild and/or domesticated animals [1]. Some zoonotic diseases are vector-borne, i.e. their causal infectious agents are transmitted by arthropods (mainly mosquitoes, ticks and sandflies). Zoonotic and vector-borne diseases are caused by a variety of pathogens, from viruses and bacteria to eukaryotes. They all have in common the presence of one or several animal host species in their biological cycle. These host species are themselves a part of an ecosystem: they are embedded in a trophic network, they live, feed, and reproduce in specific habitats or landscapes (Fig. 1) [2]. Consequently, human health is somehow, positively or negatively, related to ecosystems and landscapes [3, 4].

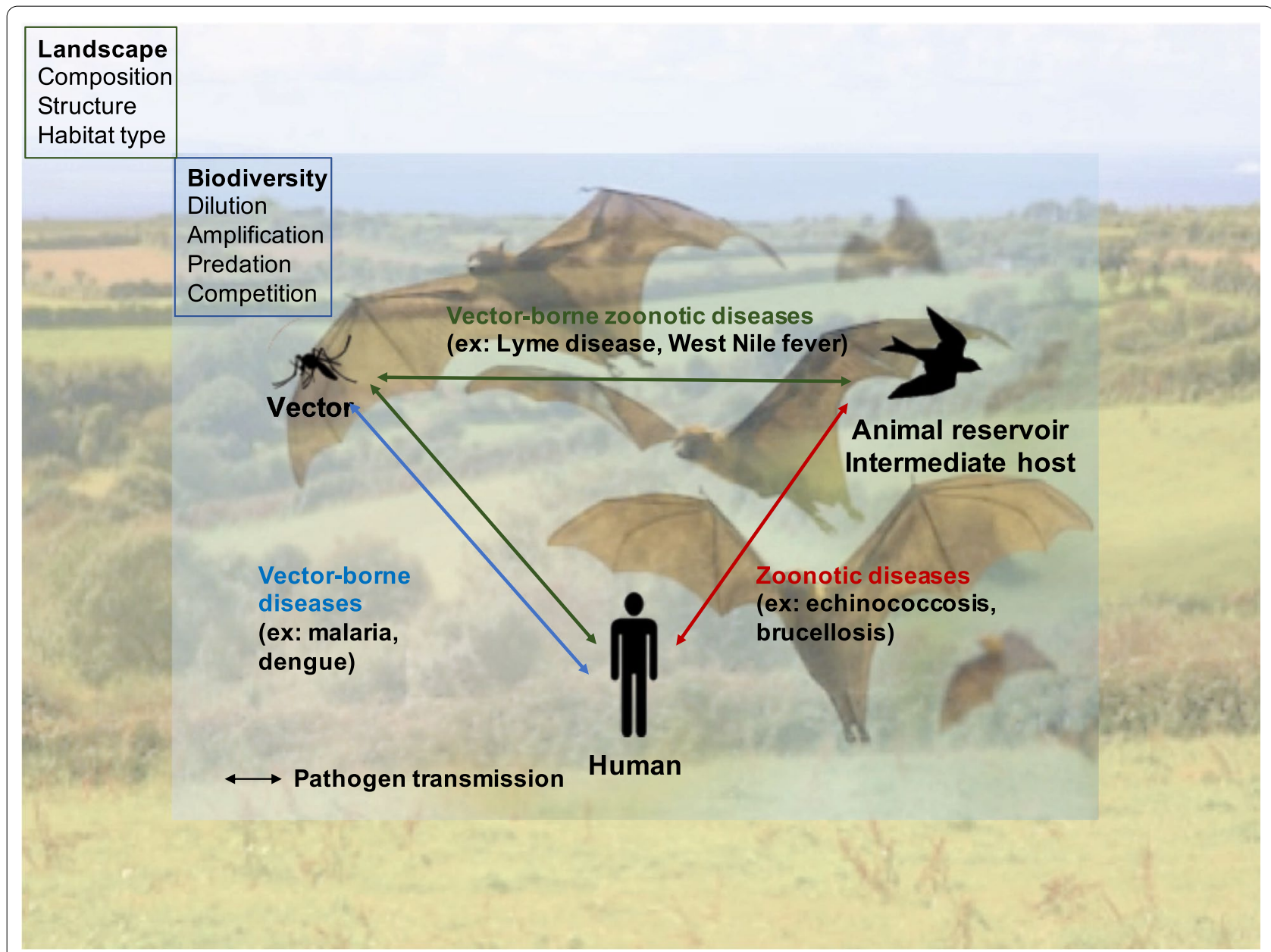

Fig. 1 Conceptual framework of the transmission of pathogens and its links with the landscape and animal biodiversity 
This idea might sound obvious and acceptable, but its inclusion into health policies at national and international scale is quite new $[5,6]$. For many decades, programs to reduce the impact of vector-borne diseases on human health have focused on chemical and physical anti-vectorial interventions, i.e. destroying vectors and their habitats or micro-habitats [7]. When there is a threat for the economy [8], crisis mitigation strategies often rely on preventive culling of livestock or of wild hosts to stop the epizooty. For example, in France, two cases of brucellosis were detected in 2012, likely caused by contacts of cows with infected ibex (Capra ibex). This led to the slaughter of 200 ibex in the Bargy mountains [9]. In 2016/2017, an epizooty of avian influenza in poultry farms in southern France led the authorities to order the preventive culling of several millions of fowl [10].

Yet, extreme measures such as these are not without limitations. The first cases of resistant mosquitoes were reported within 1 year of the first insecticide spraying campaigns for example [11, 12]. Since then, insecticide resistance of mosquitoes has spread so much that pyrethroid insecticides no longer kill mosquitoes in many places of Africa [13], and that 60 countries among the 78 included in the monitoring program of the WHO reported mosquito resistance to at least one insecticide molecule [14].

The efficacy of the control of an epizooty through the culling of wild hosts is also questionable: field studies performed 1 year after the above-mentioned culling of ibex showed that the prevalence of brucellosis in the infected ibex population had not been reduced. In fact, it even increased in the younger individuals. Moreover, given that males from surrounding non-infected populations came to "fill the blanks" left by the culling, the risk to see the infection spread to other populations was considered as high [9]. Finally, massive preventive culling, such as the one performed in 2017 to stem avian influenza, had huge socio-economical costs, and triggered ethical debates regarding the culling of millions of possibly healthy animals. Sociological studies performed in Great Britain to evaluate public opinion regarding badger culling to control bovine tuberculosis showed a widespread disapproval [15]. These limitations highlight the need for alternative control methods that would no longer be based on the direct destruction of populations or habitats, but rather on the regulation functions performed by ecosystems. With this in mind, the French stakeholders of the 3rd National Plan for Health and the Environment commissioned this review in order to synthesize existing knowledge on this topic and encourage further relevant research. These stakeholders came from the public and private sectors and included scientists, national park managers, environmental NGOs and associations, and decision makers.

Several mechanisms have already been described to explain how natural changes in species richness and abundance can regulate some diseases. Among them, the dilution effect has been particularly well studied and debated [16-20]. It states that when an ecosystem shelters a diversity of hosts, it is more difficult for a pathogen to find a highly competent host, i.e. a host in which it could multiply and be transmitted to another host, either directly or by using a suitable vector [21]. Several ecological conditions have been proposed by Ostfeld and Keesing as necessary for this dilution effect to occur [21, 22]. An amplification effect (opposite to the dilution effect) occurs when highly competent host species are favored, for example after a habitat disturbance event. Here, the highly competent host species become more abundant in the biological community and can facilitate the spread of the disease. Such response to fluctuations in host populations has been reported for the white-footed mouse Peromyscus leucopus, a highly competent host for Lyme disease [23], and the American robin Turdus americanus, a highly competent host for the West Nile virus $[24,25]$. A meta-analysis performed on 345 wetland studies by Johnson et al. [26] found that host species highly competent for the parasite Ribeiroia ondatrae, which is responsible for amphibian limb malformations, dominate in species-poor communities. Richer communities however, contain more low-competent species, which decreases the overall host competence of the ecosystem.

Another dilution mechanism is represented by some host species that have a competence close to zero, and act as "ecological traps" for the pathogen or the vector. These species are sometimes referred to as "dead-end hosts". This seems to be the case for the opossum Didelphis virginiana that kills the vast majority of ticks that become attached to it [27]. It has also been reported that the roe deer Capreolus capreolus has the ability to destroy the spirochetes of Borrelia burgdorferi in his bloodstream, preventing the infection of Ixodes ticks that feed on roe deer [28] and the spreading of Lyme disease. However, the roe deer also facilitate the reproduction of these ticks and thus potentially increase their population [29]. Illustrating the complexity of interactions between diseases and ecosystems.

Another mechanism close to a dilution effect can occur when the vector/host species competes with other species that occupy the same ecological niche but are not a vector/host of the pathogen. Johnson et al. [30] showed that an experimental increase of the diversity of snails reduced the transmission of schistosomiasis, even when the density of the snail Biomphalaria glabrata, the only host of schistosomiasis, was kept constant. 
Finally, the regulation of diseases can also occur when predation decreases populations of vectors or hosts [3133]. However, some authors suggest that not all predators are equally efficient in this respect, and that generalist predators can regulate host or vector populations more efficiently than specialized ones [34].

These various mechanisms suggest that modifications of habitats or landscapes structure, including their appropriate management, could also lead to changes in diseases incidence, by changing vector or host populations, or by altering/enhancing certain population dynamics (Fig. 1). This would rely on regulatory services provided by ecosystems. For example, a growing proportion of grasslands in agricultural landscapes have been shown to increase echinococcosis by favoring populations of intermediate hosts, grassland rodents [35], and increasing predation by the red fox Vulpes vulpes, the definitive host of echinococcosis [36]. However such ecological conditions, favorable to echinococcosis, would likely be detrimental to other diseases such as Lyme disease. In this case the red fox Vulpes vulpes is not a definitive host but acts as a regulator of rodent hosts, thus potentially decreasing the incidence of Lyme disease [32].

\section{Objective of the systematic map}

We initially aimed at providing a systematic map and a systematic review on this topic as declared in the published protocol [37]. Based on the outputs of the systematic search and the examination of studies, it appeared that a systematic review was not possible because of the very small number of articles and the high variability of both their research designs and PECO elements. The results presented herein are thus limited to a systematic map built on PECO elements and other descriptors related to study validity. Given that very little experimental studies were identified, we use Exposure rather than Intervention and PECO syntax in the following. Recommendations are given for future upgrading that would allow an evidence base to be established, when sufficient and robust data is available.

Primary question of the systematic map:

"What evidence exists on the impact of specific ecosystem components and functions on infectious diseases?".

Components of the primary questions

Population
Ecosystems, habitats, landscapes, or ecological communities in which the pathogen agent causing one of the 14 selected diseases (i.e leishmaniasis, schistosomiasis, Lyme

disease, malaria, dengue, chikungunya, Zika, West Nile, bovine tuberculosis, avian influenza, brucellosis, leptospirosis, echinococcosis, or cryptosporidiosis) is present;

Exposure/Intervention Any type of exposure/intervention susceptible to modify the biological cycle of the pathogen through modifications of habitats, landscapes, or ecological communities;

Comparator

In time, with different levels/intensities of exposure, or before/after an exposure/ intervention;

In space, between habitats, ecosystems, or landscapes with different levels/intensities of exposure, or with/without exposure/ intervention;

Outcome

\section{Methods}

This map follows the previously published protocol [37]. It has been conducted according to the Guidelines for Evidence Synthesis issued by the Collaboration for Environmental Evidence [38]. The ROSES form is included as an Additional file 1. It involved a group of stakeholders and a group of experts. The stakeholder group was composed of the commissioner (French ministry for Ecology), scientists, national park managers, environmental NGOs and associations, and decision makers. They were associated to the framing of the question and were where asked to define which diseases and ecosystem functions/ components shouldbe included in the systematic map. The expert group was composed of 20 scientific experts from French research institutions (IRD, CIRAD, Universities...), most of them co-authoring this review. The expert group provided support in building the reference set of articles to test the search equation and in the definition of the study validity criteria. 


\section{Search strategy}

Our search strategy has been designed to retrieve articles that cover a broad range of ecosystem components/ functions and diseases. We searched for articles in 5 bibliographic databases, identified as relevant by the review team and the expert panel, and listed in Bibliographic databases. In each database, we performed one search per disease. We searched in the "topic" section or in the title/abstract/keywords, wherever this option was possible. These databases were either available in open-access, or through a pre-existing subscription of FRB or the research institutions of the experts.

\section{Search terms and search string}

The search string was built based on a preliminary search conducted on Web of Science in May-June 2018. This search string was structured into three blocks related to Population and Outcomes. We chose not to use Intervention- or Exposure-related search terms, as there was a risk to miss some of them.

The 1st block of the string targeted articles mentioning the required disease or pathogen agent(s). This was the only part of the search string that differed between searches for different diseases. Synonyms of the names of the diseases, including vernacular names, were listed using the Mesh database and Google and included in the search string (list available in Additional file 2 of the protocol [37]), along with the list of pathogen agents identified for each disease. The 2nd block contained keywords related to the structure and the functioning of ecological communities. The 3rd block contained altogether generalist keywords related to ecosystems or ecology (part 3a) and a list of habitat types (part $3 \mathrm{~b}$ ) in order to retrieve specific field studies that did not mention the generalist keywords. This list of habitats was built based on the habitat classification of IUCN [39], from which we selected first-level habitats relevant for the 14 diseases included in the review (i.e. all habitats except marine habitats, rocky areas and deserts) and added synonyms.

The three elements were combined using the Boolean operators AND (both terms must be found) and OR (at least one term must appear), as follow: 1 AND 2 AND (3a OR $3 b)$.

The operator NEAR/5 (both terms must appear, with 5 words maximum between them) was used in the 2nd block. The "*" wildcard allowed to retrieve plurals and words sharing the same root such as the words "predator", "predation", "predated" (etc.) from the single word predat".

Detailed search string, as designed for Web of Science:

(Name(s) of the disease OR name(s) of the pathogen agent(s)) AND. ((species OR vector OR host OR community OR population OR prey) NEAR/5 (compos* OR structur* OR divers* OR densit* OR rich* OR abundan* OR dynamic* OR increas* OR decreas* OR chang* OR homogen* OR heterogen*)) AND.

((land" OR habitat OR ecolog* OR ecosystem* OR predat" OR wildlife OR "wild life" or "wild animals" OR "wild fauna" OR biodiversity OR "dilution effect") OR.

(forest* OR shrub* OR scrub* OR wood* OR grass* OR pasture* OR arable* OR wetland OR peat" OR grove OR hedgerow OR mangrove OR savanna* OR bush OR bushes OR ricefield OR "rice fields" OR paddy OR plantation OR tundra OR pond OR canal OR ditch OR river OR stream OR creek OR bog OR marsh OR swamp OR fen OR lake OR oases OR delta OR mountain OR cave OR estuary OR dune OR lagoon OR island OR garden OR park OR "green areas")).

This search string was approved by the expert panel. It was adapted to the specific requirements of each bibliographic database (Boolean operator accepted, maximum number of words). When it had to be reduced, we gave priority to the 1st and 2nd blocks of the search string. The search string used in each database is reported in Additional file 2 to ensure replicability and facilitate future upgrading.

\section{Language}

We searched for literature in English and in French. This allowed us to screen most of the peer-reviewed scientific literature as well as research published in French and relevant to the French context. Contrary to what was announced in the protocol, we could not search for literature in Spanish for leishmaniasis and schistosomiasis, due to time limitation.

In institutional websites, searches were performed in English for international institutions, and in French for French institutions.

\section{Bibliographic databases}

Publications were collected from the following databases, using subscriptions from the institutions of authors and co-authors (MNHN, CNRS, IRD, CIRAD, Universities):

- OpenGrey

- PubMed

- Science Direct

- Scopus

- Web of Science Core Collection (all years 1956 2018, all citation indices) 


\section{Assembling a library of search results}

Using the reference management software Zotero ${ }^{\circledR}$, all exported articles were organized into separate collections, one for each disease. Once all the searches were completed (one for each disease and in each database), references for each search were archived in a unique database, and duplicates were removed.

\section{Grey literature}

To minimize the risk of publication bias, we asked scientists from the expert panel and the stakeholder committee to share grey literature and unpublished data. We also conducted a search for grey literature in the 13 organizational websites previously identified [37]. Most of these websites did not allow for complex searches, nor restricted search to title or abstract of the documents. As a consequence, the searches generated a large number of results $(n=565)$. We screened the first ten results for each of the 14 diseases in each website. Given that none of them were relevant, we did not continue the screening due to time limitation.

\section{Article screening and study eligibility criteria}

Articles retrieved from the bibliographic search were screened based on their title, abstract and full text based on PECO elements. An additional step of screening was performed to include relevant study validity criteria in the systematic map (detailed in the Screening process section). No deviation from the protocol was made regarding the screening process or the eligibility criteria.

\section{Screening process}

The screening of titles, abstracts and full-texts were performed by the project leader (LL) and two assistants (LB, BL). Eligibility criteria were proposed by the project leader and validated by the expert panel.

Consistency checking Prior to the beginning the screening, the 3 screeners independently examined the titles of 42 articles ( 3 per disease) randomly extracted from those retrieved by the search equation.

The same exercise was conducted on 28 abstracts ( 2 per disease). Results of the tests for agreement conducted for title- and abstract-screening are presented in Additional file 3, along with the Kappa scores obtained.

No consistency checking of the screening was performed at full-text stage, but a double-checking of fulltexts screened by the two assistants was performed by the project leader (40\%, 360 out of 936 papers). Disagreements were resolved by discussion. Twenty-five articles initially retained were rejected, while nine articles initially rejected were retained.

\section{Eligibility criteria}

Different eligibility criteria were applied at title, abstract, and full-text stages. When the information provided by the title or abstract was $n$ insufficient to reject or retain the article with certainty, it was retained and examined at the next screening stage.

Title: Inclusion criteria: Presence of the name of the disease or pathogen agent responsible for this disease, OR presence of a generic term related to infectious diseases or pathogens;

For vector-borne diseases only: presence of the name of the vector or a generic term related to vectors (e.g. mosquitoes, ticks, vectors).

Exclusion criteria: Absence of the above-mentioned elements OR indication that the article is a review, a meta-analysis, an opinion paper, an ex-situ study (with the exception of mesocosm) or theoretical modelling.

Abstract Inclusion criteria: Presence of words related to ecosystem components, functioning, or management;

Exclusion criteria: Similar to criteria for title screening, OR elements showing that the paper is only a descriptive study (no exposure/intervention, no comparator); OR destructive intervention targeted towards a vector or a host; OR intervention nonrelated to ecosystems, such as individual prophylaxis, micro-habitats removal (tires, flower pots), spraying of organic insecticides, genetic modifications of vectors, etc.

Full text Inclusion criteria: Outcome obtained from field data (e.g. vector/host collection on the field, epidemiological database from hospitals) AND presence of all PECO elements detailed in the section "Definition of the question components"; Exclusion criteria: Similar to those applied for title or abstract screening; OR effect of Exposure on Outcome purely descriptive (no statistics); OR elements informing that the Outcome is an output of a theoretical mathematical model that does not use primary data OR Outcome obtained in laboratory.

The list of articles excluded at full-text is presented in Additional file 3 (worksheet 1), as well as the reason for their exclusion.

\section{Study validity assessment and consistency checking}

Selection of studies for validity assessment Before conducting validity assessment, we further selected studies based on characteristics that were not anticipated in the protocol and required thorough reading of the articles. Exclusion of certain studies was decided by the project 
leader in consultation with $\mathrm{LB}$ and $\mathrm{BL}$ when the authors reported that prevalence or incidence of the disease was too low to allow for any robust conclusion $(n=4)$, and when the study was only descriptive and no statistics were available $(n=4)$. We also excluded the "disease $x$ exposure" combinations that were only represented by a single study $(\mathrm{n}=94)$ in order to priorize combinations reporting replications that would allow for synthesis. The list of the 94 studies with a unique "disease $x$ exposure" combination can be found in Additional file 4. (Worksheet 2).

Study validity assessment Validity assessment was performed to account for limitations in the research design when several studies were identified for a "disease $\mathrm{x}$ exposure" group. When an article contained several studies, the validity assessment was carried out separately for each of them.

Study validity relied on four main aspects of research design, as decided by expert consultation:

- the spatial coherence between exposure and outcome;

- the temporal coherence between exposure and outcome;

- the degree of replication in time;

- the degree of replication in space.

These four criteria aimed to evaluate whether the spatial and temporal aspects of exposure and outcome were relevant enough to allow any conclusion about the evidence of a potential effect of the exposure on the outcome. These four criteria are detailed in Sect. 3.2.4 Data coding strategy.

To evaluate whether studies included in the same "disease $\mathrm{x}$ exposure" group reported similar or variable findings, a narrative summary of individual study findings was provided (columns $\mathrm{M}$ and $\mathrm{N}$, Additional file 5, worksheet Validity assessment) based on the information contained in the result section of studies. The study findings were classified in two categories: "significant study findings" are those for which authors reported a $p$-value inferior to 0.05 . Non-significant study findings are those for which authors reported a $p$-value superior to 0.05 . In case of missing or unclear information or purely observational results without any statistics, the article was excluded from further analysis [40-42].

When variability was observed among results of articles from the same "disease $\mathrm{x}$ exposure" group, the four criteria used for validity assessment were analyzed to assess whether they could explain the diversity of results.

Consistency checking For the 114 studies that were included in validity assessment, meta-data extraction and
Table 1 Detail of the exposures

\begin{tabular}{ll}
\hline Exposures (Ecosystem components/functions) \\
\hline Landscape-related & Landscape composition* \\
& Forest fragmentation \\
Habitat-related & Type of habitat* \\
& Vegetation cover \\
& Habitat perturbation \\
& Distance to habitat* \\
Animal biodiversity-related & Predation \\
& Host species richness/diversity \\
& Wild host density \\
& Domestic host density \\
& Intermediate host density \\
& Contact with wildlife \\
& Proximity with host species \\
& Community composition
\end{tabular}

coding was performed by the project leader for 64 studies, and by research assistants for 50 studies. For these 50 studies (45\%), the project leader conducted a doublecheck of meta-data extraction, coding and attribution of validity level. Discrepancies were discussed in order to reach an agreement.

\section{Data coding strategy}

Meta-data coding and extraction for mapping was performed by the project leader. Ten percent of the 207 articles $(n=20)$ were double-checked by a co-author to ensure that there were no errors in meta-data extraction and coding. Meta-data were extracted from all articles retained after the screening process $(n=207$, including 216 studies). The following information was extracted and stored in an Excel database (Additional file 5, Worksheet "Systematic map"):

- Title

- First author

- Year of publication

- Country

- Continent

- Disease

- Type of ecosystem component/function

- Detailed ecosystem component

- Outcome measured in vector (yes/no)

- Outcome measured in intermediate host (yes/no)

- Outcome measured in non-human final host (yes/ no)

- Outcome measured in human (yes/no)

The "Country" column contains the name of the country/countries where the field study was performed or where the data was collected. The code 
"continental-scale" or "global-scale" was attributed to studies run across a very large geographical scale.

The coding of the name of each disease follows the list presented in the section Question components.

Ecosystem components/functions were described according to the categories presented in Table 1. Some broad categories (e.g. landscape composition) are labelled with an asterisk (*) and detailed in the column "Detailed ecosystem component" (e.g. proportion of forest). Note that for these categories, it is the detailed ecosystem component(s) that was used to form the "disease $\mathrm{x}$ exposure" combination(s) based on which studies were included or excluded from validity assessment (see Sect. 3.2.3).

To facilitate the use of the map, epidemiological outcomes were coded in 4 different columns, signaling where measurements have been conducted (in vector and/or intermediate host and/or non-human final host and/or human).

Data coding strategy for validity assessment For the 114 studies for which a validity assessment was conducted, we extracted meta-data related to the 4 criteria used for validity assessment. The coding strategy used for metadata extraction is described hereafter for the 4 criteria:

1/ Spatial coherence: When the outcome was measured in humans, a study was considered as highly valid when the place of contamination could be identified (e.g. location of the tick bite for Lyme disease). Low validity was attributed when it could not (e.g. use of residential address of the patient for Lyme disease).

For animal host-related exposures, high validity was attributed when the sampling was performed on an area coherent with the home-range of the host. Medium validity was attributed when the sampled area was considered too small with regards to the home-range of the host (e.g. deer abundance index based on dung sampling on less than an acre), or too large (e.g. host abundance index extracted from a county-scale database and attributed to field sites). Low validity was attributed whenever important information was missing to assess spatial coherence.

For landscape-related exposures, the level of validity depended on the spatial scale at which the analysis was performed, and on the spatial definition of the land-use data. High validity was attributed when the spatial scales of the landscape analysis matched the ecological range of the vector or host of the pathogen. Where it did not match, the study was considered to be of medium validity. Medium validity also characterized macro-scale studies (e.g. studies with outcome and exposure averaged by counties, regions or states) and studies that used land-use data with a low spatial resolution $(<100 \times 100 \mathrm{~m}$ pixels $)$. Low validity was attributed when important information was missing to appraise the spatial coherence (e.g. no information on the spatial resolution of a land-use database, or on the scale of landscape analysis around sampling plots).

2/ Temporal coherence: For landscape-related exposures, the level of validity reflected the risk that the exposure significantly changed between the exposure and outcome assessments (e.g. due to urbanization, deforestation, fragmentation etc.). High validity was attributed to a study when the exposure and the outcome were assessed within the same year; medium validity when they were assessed less than 5 years apart, and low validity when the delay was superior or equal to 5 years. An exception to this rule was made for echinococcosis that has a long latency period in humans (3 to 15 years): high validity was attributed when ancient and long-term landuse data were used (from 20 to 3 years before the outcome measure). Otherwise, validity was assessed as low.

For animal hosts-related exposures, the level of validity was attributed according to the temporal coherence between exposure and outcome measures, with respects to the biological cycles of the pathogen and/or the vector and/or the animal host(s). As a general rule, high validity was attributed to studies when the exposure and the outcome were assessed during the same year, else a medium validity was attributed. There were a few exceptions to this rule:

- For echinococcosis infection in dogs and foxes, which can be detected for a maximum of one month after the ingestion of a contaminated rodent, high validity was attributed when the outcome was measured less than one month after the exposure (e.g. rodent density). Otherwise, a low validity was attributed.

- For studies on Lyme disease, in which exposure was measured in rodents or cervids and the outcome in ticks, validity depended on whether the timing inherent to the tick life cycle is taken into consideration. Indeed, it is expected that rodents are hosts to larvae and nymphs while cervids are a preferential host for adult ticks. To test for an effect of deer density on nymphal infection prevalence, one should use data on deer density collected 2 years before the outcome was measured. We attributed a high validity to studies that took such a delay into account (1 year between exposure in cervids and outcome in larvae or between exposure in rodents and outcome in nymphs; 2 years between exposure in cervids and outcome in nymphs, or between exposure in rodents and outcome in adults, or between exposure in rodents and outcome in humans; 2 to 3 years between exposure in cervids and outcome in humans). 
When the exposure or outcome involved assessments on vectors or hosts with a known peak of activity (e.g. ticks and mosquitoes) or peak of detection (e.g. breeding period for birds), the level of validity was attributed in order to minimize detection bias: "high" when measures were conducted during the peak, "low" when they were conducted outside of the peak.

For longitudinal studies, low validity was attributed when the sampling period across sites lasted for more than a month, without being justified by differences in phenology (e.g. in the case of a high latitudinal gradient between sites). Indeed, this could introduce a potential bias between sites sampled early versus those sampled late in the season. Low validity was attributed whenever important information was missing to appraise the temporal coherence (e.g. date of measure).

3/ Temporal replicability: High validity was attributed when the study was based on more than 5 years of data collection regarding the outcome and animal biodiversity-related exposures. A medium validity level was attributed to studies with 2 to 5 years of data collection, and a low validity to studies based on data collected over only 1 year. This did not apply to landscape-related variables that are not expected to fluctuate strongly inbetween years.

4/ Spatial replicability: A high validity was attributed to studies that included more than 20 study sites (or replicates per treatment, or spatial units in the case of macro-scale studies). Those based on 6 to 20 sites were considered to be of medium validity, and a low validity was attributed to studies based on five sites or less.

To facilitate the narrative synthesis, the validity levels (high, medium, low) attributed for the 4 criteria were used to allocate a global validity level to each study with the following categories:

$\begin{array}{ll}\text { High } & 4 \text { 'high'. } \\ \text { Medium/High } & 3 \text { 'high' or } 2 \text { 'medium' and 2 'high'. } \\ \text { Medium } & 4 \text { 'medium' or } 3 \text { 'medium' or 2 'high' } \\ & \text { and 2 'low', or mix of 'high,' 'medium' } \\ & \text { and 'low' } \\ \text { Medium/Low } & 3 \text { 'low' or 2 'medium' and 2 'low' } \\ \text { Low } & 4 \text { 'low'. }\end{array}$

For each article retained at this stage, the levels of validity attributed to the 4 criteria and their justification can be found in Additional file 5, as well as the global level of validity.

\section{Data mapping method}

In the first part of the systematic map ("Mapping the quantity of studies"), studies were collated based on $1 /$ the disease they studied, 2/ the continent on which they were conducted, and 3/ the type of exposure they studied. A heatmap of the "disease $x$ exposure" combinations of the 216 studies was used to highlight knowledge gaps and clusters. In the second part of the map ("Mapping the quality of studies"), the findings of studies included in the same "disease $x$ exposure" group were presented as a narrative synthesis and potential differences in these findings discussed based on the results of validity assessment.

\section{Findings \\ Descriptive statistics \\ Literature screening}

The bibliographic searches in scientific databases were performed on the following dates: 24/10/2018 (PubMed, Science Direct), 25/10/2018 (Open Grey), and 5/11/2018 (Web of Science, Scopus). For each database, the searches for the 14 diseases were performed on the same date.

All the steps of the screening process are presented in Fig. 2 (see Additional file 2 for the detailed screening for each disease). The searches for the 14 diseases generated a total of 12,627 articles. After eliminating duplicates $(\mathrm{n}=2904), 9723$ articles were screened. $1835(19 \%)$ were rejected at title stage, $6945(71 \%)$ at abstract stage, and $641(6 \%)$ at full-text stage (see Additional file 4 for the list of articles rejected at full-text with reason for rejection). Note that 95 full-texts with relevant abstracts could not be found and thus were not screened (list presented in Additional file 4). The final corpus for systematic map was constituted of 207 articles that studied 13 diseases out of the 14 initially selected. No relevant article was found for Zika.

Searches for grey literature on institutional websites were performed between January 15th and February 18th 2019. No documents found in the grey literature search were relevant, and so none were included in the final corpus.

\section{Mapping the quantity and characteristics of relevant studies}

The systematic map presents 207 articles (216 studies) about the effects of ecosystem components or functions on 13 of the 14 diseases. All were written in English and were published in scientific journals, except for 2 articles that were part of an unpublished $\mathrm{PhD}$ manuscript. Ninety-five percent were published after 2000, and 65\% after 2010. Studies were spread across 5 continents, with 68 studies from North America, 54 from Europe, 35 from Asia, 30 from Africa, 22 from South America, 4 from Middle-East and 3 from Oceania (Fig. 3). Seven articles contained several studies performed on different continents. Two studies were conducted at a global-scale.

Lyme borreliosis was the most studied disease, with 64 studies from Europe $(\mathrm{n}=34)$ and North America 


\section{ROSES flow diagram}

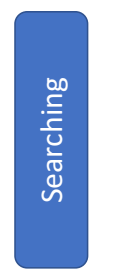

Records identified through database searching $(n=12627)$
Records identified through other sources, listed $(n=0)$
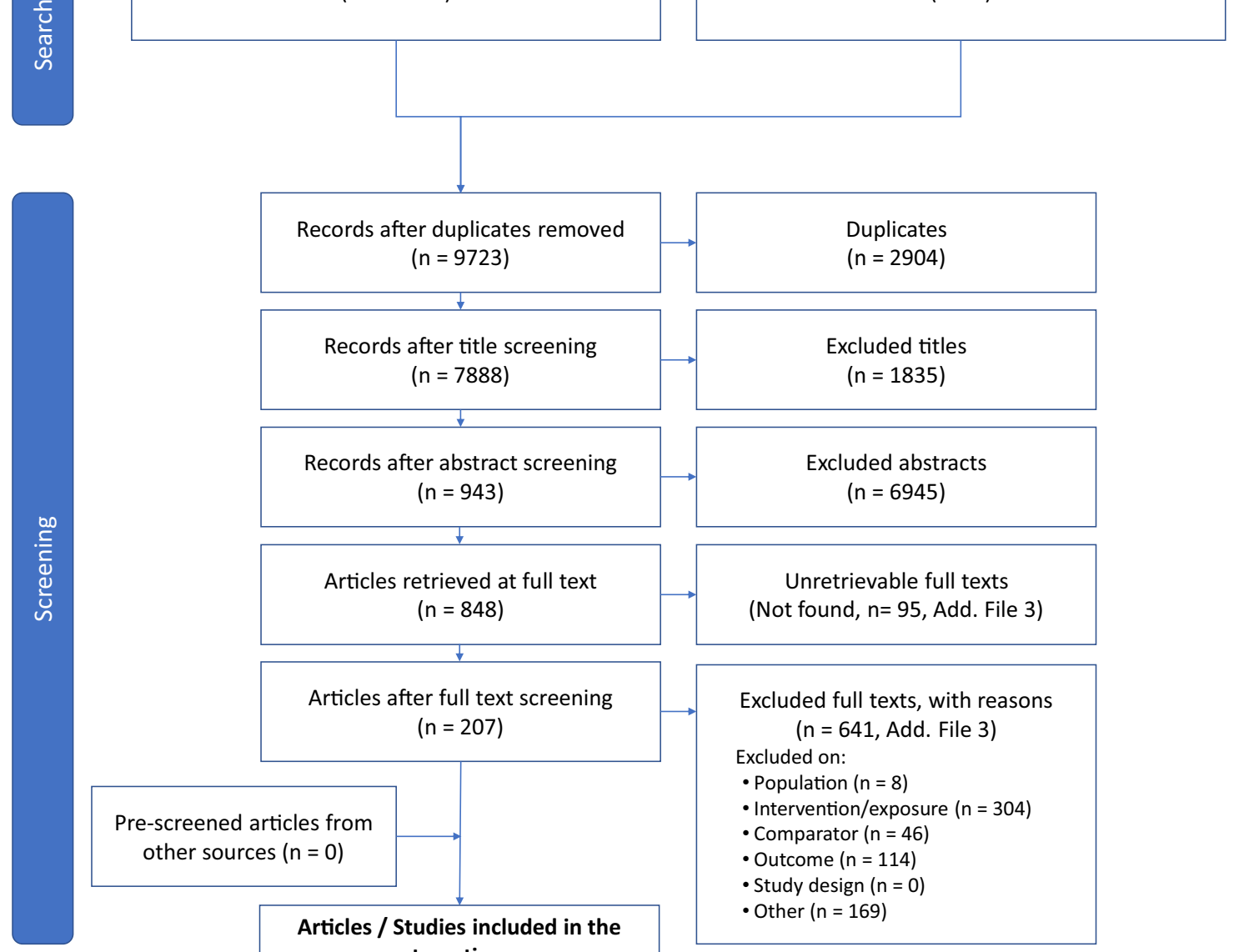

Records after title screening $(n=7888)$

Excluded titles $(n=1835)$

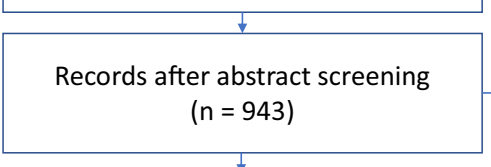

Excluded abstracts $(n=6945)$

Articles retrieved at full text $(n=848)$

Articles after full text screening $(n=207)$

Pre-screened articles from other sources $(n=0)$

Articles / Studies included in the systematic map

Articles $(n=207 / n=216)$ (Not found, $n=95$, Add. File 3 )

Excluded full texts, with reasons $(n=641$, Add. File 3 )

Excluded on:

- Population $(n=8)$

- Intervention/exposure $(n=304)$

- Comparator $(n=46)$

- Outcome $(n=114)$

- Study design $(n=0)$

- Other $(n=169)$

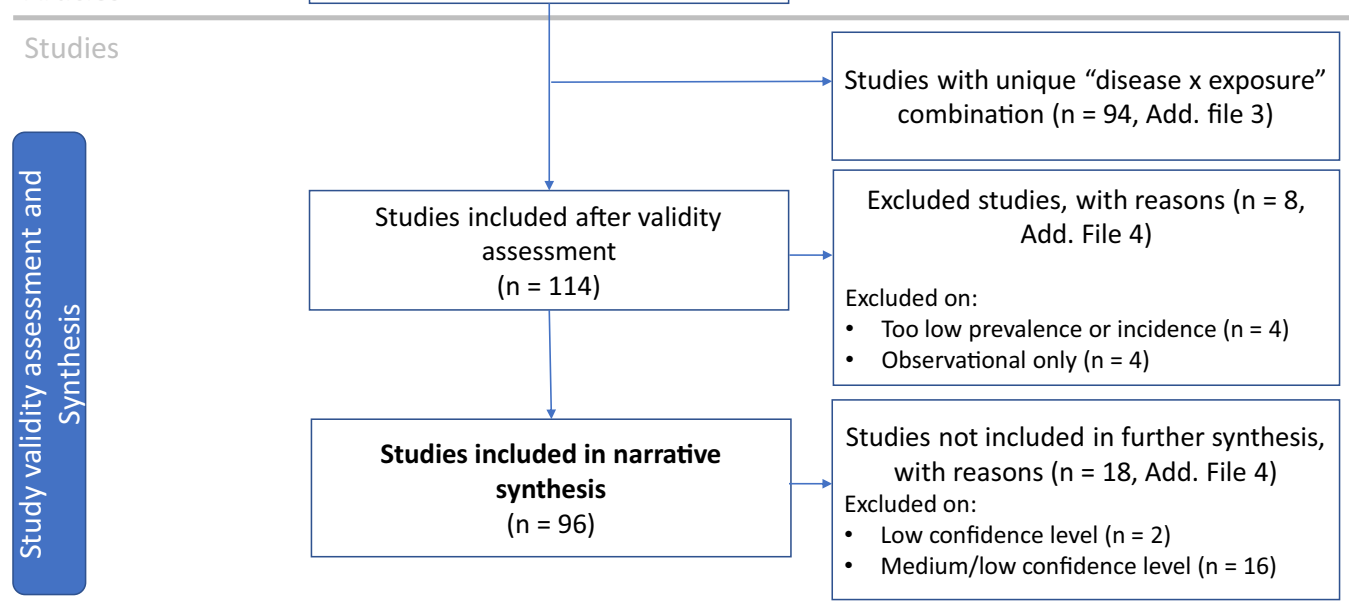

Fig. 2 Results of the bibliographic search and screening of articles for all 14-diseases 


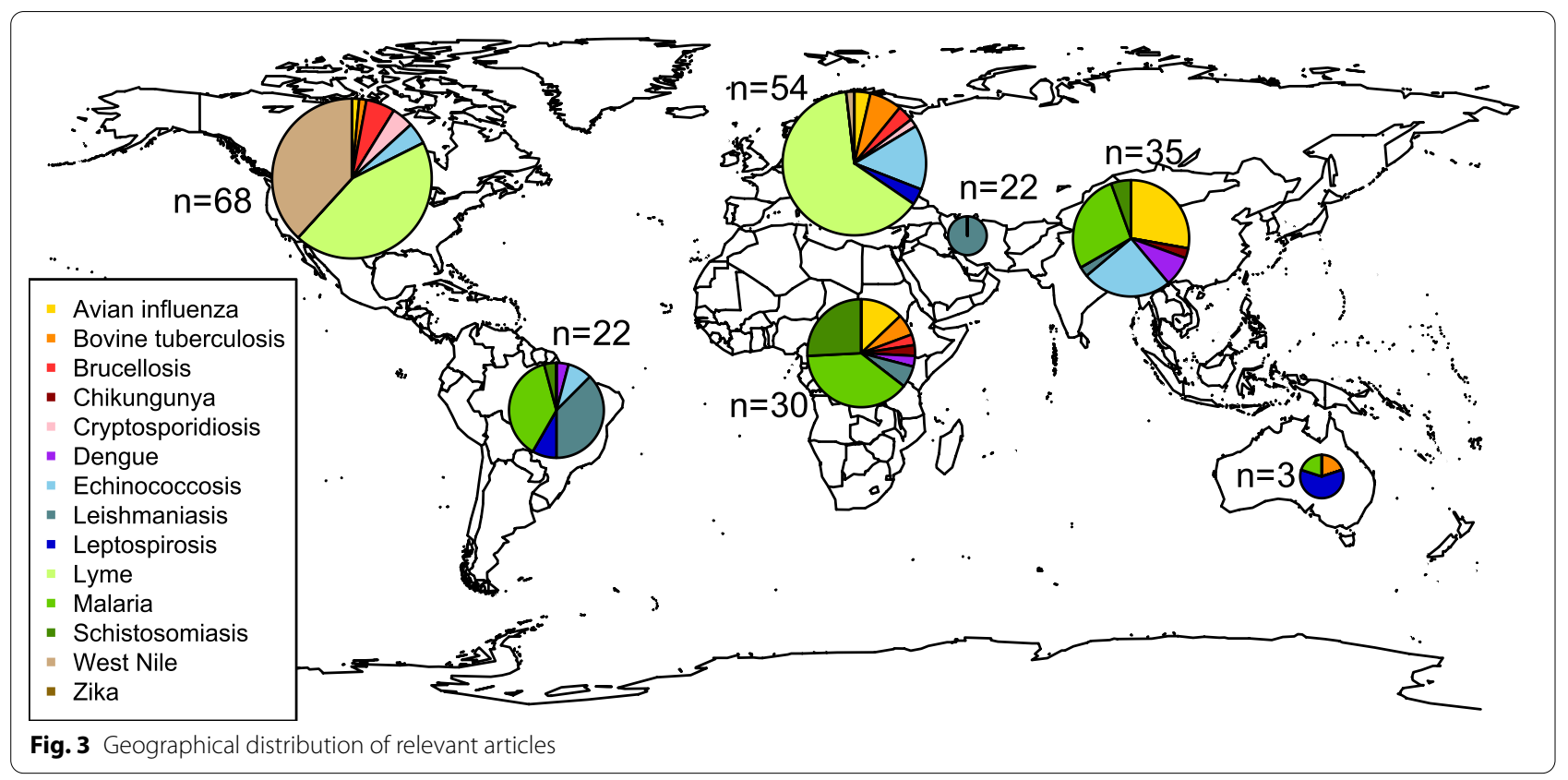

$(\mathrm{n}=30)$. Followed by malaria, with 29 studies equally distributed between Africa $(n=11)$, Asia $(n=9)$ and South America $(n=8)$. West Nile gathered 26 studies, all conducted in North America except for one. Echinococcosis was mentioned in 20 studies, mainly from Asia $(n=9)$ and Europe $(\mathrm{n}=8)$. Leishmaniasis was the subject of 15 studies, mostly from South America $(\mathrm{n}=8)$ and MiddleEast $(n=4)$. Avian Influenza was mentioned in 12 studies, with a large majority from Asia and Africa $(n=10)$. Schistosomiasis was reported in 9 studies, with a majority of studies conducted in Africa $(n=6)$. The 3 mosquito-borne diseases transmitted by Aedes sp. accounted for less than 10 studies altogether, equally distributed between Asia and Africa ( 5 for dengue, 2 for Chikungunya, 0 for Zika).

Bovine Tuberculosis was examined in 9 studies from 4 continents (Africa, Europe, North America and Oceania). Brucellosis was the subject of 7 studies conducted in Africa, Asia, Europe and North America. Leptospirosis was reported in 5 studies, from various continents (Europe, North America, Oceania and global-scale), while cryptosporidiosis was present in 4 studies conducted in North America $(\mathrm{n}=3)$ and Europe $(\mathrm{n}=1)$.

With the exception of eight studies that were based on controlled experiments (6 BACI field studies [43-48] and 2 mesocosm experiments [30, 49]), all others relied on correlations based on post-hoc observational designs.

\section{Mapping the quality of relevant studies (narrative synthesis including validity assessment)}

In this section, we describe the types of exposures and outcomes reported in the relevant studies for each disease. Among the 216 relevant studies included in the systematic map, 100 were excluded from the validity assessment and further narrative synthesis as they met the exclusion criteria listed in Sect. 3.2.3: )1) 94 were unique in the "disease $x$ exposure" combination they studied and could not be included in any group for synthesis (they are listed in Additional file 4), (2) 4 studies (3 articles) found too little infection to perform any further analysis (highlighted in red in Additional file 5, worksheet Systematic map), (3) 4 studies lacked statistical tests and reported purely observational results. The remaining 114 studies were organized into 34 groups to allow for validity assessment and narrative synthesis. This covered 9 out of 14 diseases, and each group contained 2 to 16 studies. Further details including validity based on the four criteria presently previously and the final global level of confidence can be found in Additional file 5 (worksheet Validity assessment). For each group, results from studies with a high, medium/high and medium validity are synthesized in a narrative form and potential differences in results are discussed. Eighteen studies that were attributed a medium/low or low validity were excluded from the synthesis (Additional file 5, worksheet Validity assessment).

In the following section, diseases are presented in alphabetic order and exposures are presented in two sub-sections: landscape-related and animal biodiversity-related exposures. 


\section{Avian Influenza}

Twelve studies were retained for this disease (Additional File 5). All of them used epidemiological data collected in avian hosts, and two of them also used epidemiological data collected in humans $[50,51]$.

\section{Landscape-related exposures}

Ten studies looked at the composition of the landscape around recorded cases and searched for a correlation between the proportion of various types of land-use and epidemiological data. Exposures included: proportion of riceland ([50, 52-54]; group 1 in Additional file 5$)$, proportion of waterbodies ([50-52, 50$52]$; group 2), proximity to waterbodies ([52, 53, 58]; group 3), and Normalized Difference Vegetation Index (NDVI), used as a proxy for vegetation cover or climate ([54, 58-60]; group 4).

Group 1 (\% of riceland): The studies were limited in time to a few years, and spatially to a few areas, but the spatial replication level at these sites was high for all studies. The results reported are heterogeneous. Two studies reported a positive correlation between the proportion of riceland in the landscape and avian influenza outbreaks, but that was not verified in all the regions studied [52, 53]. Pfeiffer et al. [54] also found a significant correlation, while Yupiana et al. [50] reported an absence of correlation.

Group 2 (\% of waterbodies): The results in this group were highly variable. Among the three studies that were attributed a medium/high validity, some reported an absence of correlation between the proportion of waterbodies and avian influenza infection [51, 57], while others reported a positive correlation [51, 56]. A similar variability was observed among the four studies with a medium validity, in which authors reported a positive correlation $[50,52,54,55]$ or an absence of correlation $[52,54]$. Overall, the link between waterbodies and avian influenza in poultries seems to be highly variable in space (between study regions) and in time (between epidemic waves). The fact that each study uses its own type of waterbody class (ponds, or streams, or lakes, or all waterbodies combined) likely adds an additional source of variability.

Group 3 (proximity to waterbodies): The three studies of this group had very close validity profiles and only differed in the effort of replication in the observations.. As in the previous group, the studies did not target the same habitats (lakes [52] vs. all types of permanent waterbodies $[53,58])$, which could be a factor of variability. Variability was also reported within two studies: the proximity to waterbodies was found to be a risk factor for poultry infection in three out of four study regions in Paul et al. [53], and only in one site and during one out of two epidemic waves in Saksena et al. [52]. Again, these results suggest that the link between waterbodies and avian influenza in poultries seem to be highly variable in space (between study regions) and in time (between epidemic waves).

Group 4 (vegetation cover): The four studies retained in this group had high replication in space but lacked high temporal replication and spatial coherence. The study with the highest validity reported that the risk of outbreak in poultry was lower in sites with high NDVI values [59]. The results from the three studies with a medium validity are difficult to analyse. Indeed, in one of them [58], the spatial resolution of the vegetation data was quite low (1 km grid), while it was not mentioned in the two other studies $[54,60]$. The lack of robust studies with high quality data is the main limit to establish a potential link between avian influenza and vegetation cover.

\section{Animal biodiversity-related exposures}

Gaidet et al. [61] studied the composition of the wildfowls community and its effect on the infection in wildfowls. Two studies looked at the contact between poultry and migratory waterbirds, to test whether outbreaks in poultry were co-occurring temporally and spatially with migratory routes $([55,60]$; group 5$)$.

Group 5 (contact with wild birds): Newman et al. [60] and Takekawa et al. [55] were attributed a very high level of validity for all but one parameter, due to an absence of temporal replication. They found similar results, indicating an absence of correlation between the presence of migratory birds and the infection of poultry.

\section{Bovine tuberculosis}

Nine studies were retained for this disease (Additional file 5).

\section{Landscape-related exposures}

Among landscape-related exposures, two variables were studied to search for an effect on cattle infection: the proportion of grasslands ([62, 63]; group 6) and of forests ([63, 64]; group 7) in the landscape. A fifth study (Walter [65]) focused on the effect of the proportion of wetlands in the landscape on cattle infection.

Group 6 (\% of grassland): The two studies in this group were attributed a medium/high validity, although Bekara et al. [62] was of higher validity due to replication and temporal coherence. The results they obtained were different. Bekara et al. [62] reported a significant positive correlation between the proportion of permanent grasslands on the farm and cattle infection, while it was not significant in Bouchez-Zacria et al. [63], whose outcome was quite different (concomitant infection of cattle and badgers). 
Group 7 (\% of forest): The studies were both rated as "high" for their spatial coherence and replication but reported variable results. Porphyre et al. [64] reported a positive effect of the proportion of forest in a $200 \mathrm{~m}$ radius around farms on cattle infection whilst BouchezZacria et al. [63] found no effect of the proportion of forest in $500 \mathrm{~m}$ and $1000 \mathrm{~m}$ radii around badger setts on the concomitant infection of cattle and badgers. As the research designs were very different between the two studies, it is difficult to draw any accurate conclusions without further analysis.

\section{Animal biodiversity-related exposures}

Three studies tested the effect of host species richness on the infection in cattle or wild hosts ([66-68]; group 8 ). Four studies investigated the effect of the density of wild hosts on the infection by bovine tuberculosis. However, they all assessed exposure and outcome in a different host species (deer, wild boar and badger for the exposure; cattle, wild boar, deer and badger for the outcome), thus preventing useful synthesis. Three studies focused on different cattle/wildlife interfaces in Africa in order to determine if the degree of contact between domestic and wild hosts had an effect on cattle infection, but one was excluded because prevalence of infection was too low [69] leaving a group of two studies ([66, 67]; group 9).

Group 8 (host species richness/diversity): The three studies included in this group differ greatly in their spatial and temporal validity. Their results are different. Sintayehu et al. [67] observed different correlations between mammal species richness and cattle infection depending on the analysis (univariate vs multivariate). Huang et al. [66] reported that a high mammal species richness reduced the positive correlation between cattle density and cattle infection but did not find any effect of high mammal species richness when tested alone. Santos et al. [68] reported an absence of dilution effect after testing for a correlation between species richness of wild ungulates and wild boar infection.

Group 9 (contact with wildlife): The studies conducted by Sintayehu et al. [67] and Huang et al. [66] were both attributed a medium/high validity. However, the spatial and temporal coherence was "high" in Sintayehu et al. [67] and considered robust, while it was only "medium" in Huang et al. [66]. The results from these two studies are different. Sintayehu et al. [67] found that habitat use overlap between cattle and greater Kudu was correlated with cattle infection, while Huang et al. [66] did not find any correlation when testing similar variables, yet he reported a significant correlation between the contact with buffalo and cattle infection. However, the interactions between cattle and greater Kudu were not directly observed in Huang et al. [66] but inferred from distribution maps, a method that might be less robust than the direct field observations made by Sintayehu et al. [67].

\section{Brucellosis}

Seven studies were retained for this disease (Additional File 5). Studies on the density-dependence of the disease were discarded during the screening process, as they were out of our scope, at the exception of one study that also contained a habitat-related exposure [70]. Only one study assessed the outcome in humans while the other six assessed it in animal hosts.

\section{Landscape-related exposures}

Three studies investigated landscape-related exposures: type of habitats [70], landscape composition [71], vegetation cover [72].

\section{Animal biodiversity-related exposures}

Five studies investigated the interface between domestic and wild hosts: Brennan et al. [73] and Nina et al. [74] studied the effect of wild host densities (respectively measured in elk and in African ungulates) on cattle infection, while Muñoz et al. [71] tested the effect of domestic host density (pigs) on wild boar infection. Finally, Caron et al. [69] collected epidemiological data both on domestic and wild hosts (respectively cattle and African buffalos) at different interfaces that varied in the level of contact between domestic and wild hosts. The study by Ferrari et al. [75] was the only one focused on wild animals, which looked at the effect of bison density on elk infection. Overall, exposures were too different to form a group for synthesis.

\section{Chikungunya}

Two studies were retained for this disease (Additional file 5).

\section{Landscape-related exposures}

Sheela et al. [76] tested the effect of landscape composition (percentage of various land-use types) on human incidence, while Diallo et al. [77] measured infection from the mosquito vector and searched for an effect across habitat type (forest, barren, savannah, agriculture and village). These two studies were too different in the land-use types they compared to form a group for synthesis. 
Animal biodiversity-related exposures

No study investigated exposures related to animal biodiversity.

\section{Cryptosporidiosis}

Four studies were retained for this disease (Additional file 5).

\section{Landscape-related exposures}

No study investigated exposures related to landscapes or habitats.

\section{Animal biodiversity-related exposures}

Jagai et al. [78] focused on the effect of the density of domestic hosts (cattle) on the prevalence in human beings. The three other studies assessed the effect of wild host-related exposures on the infection of wild hosts, but differed in the type of exposure studied: Kilonzo et al. [79] studied wild hosts species richness, while Bajer et al. [80] and Atwill et al. [81] studied the effect of wild host density, in rodents and feral pigs, respectively. Overall, exposures were too variable to form a group for synthesis.

\section{Dengue}

Five studies were retained for this disease (Additional file 5). In all five studies, the outcome was measured in humans $[76,82-85]$. One study also measured the infection in mosquitoes [82].

\section{Landscape-related exposures}

The types of ecosystem components studied were very variable: Bett et al. [82] compared three different habitats (irrigated, pastoral, riverine) to test the effect of irrigation on the disease. Acharya et al. [85] studied the effect of vegetation cover, using NDVI as a proxy, while Araujo et al. [84] also studied the effect of NDVI, but instead as a proxy for heat ("urban heat island effect"). Finally, three studies looked at the effect of landscape composition on human cases $[76,83,85]$. Although they differed in the way they characterized natural and semi-natural landuses, they all included the proportion of urban land-use among tested variables (group 10).

Group 10 (\% of urban land-use): One of the studies was attributed a medium/low validity and was excluded from synthesis [76]. In the two remaining studies, results are homogenous and seem to confirm the initial hypothesis: Acharya et al. [85] was considered the most valid, with high levels of spatial and temporal replication. It reported an increased incidence of dengue in humans when the proportion of urban land-use in the landscape increases. Tiong et al. [83] found a similar correlation, although this study was considered less valid as it lacked temporal replication and had limited spatial replication, and the strength of the correlation varied according to regions.

\section{Animal biodiversity-related exposures}

No studies investigated exposures related to animal biodiversity.

\section{Echinococcosis}

Twenty studies were retained for this disease (Additional file 5). Six studies focused specifically on landscaperelated exposures compositions, while the other mixed landscape-related exposures and animal biodiversityrelated exposures.

\section{Landscape-related exposures}

Eight studies tested the effect of the proportion of grasslands in the landscape on the infection in humans ([35, 86-92]; group 11). The study from Qian et al. [93] was not included in this group as it focused on a slightly different exposure (i.e. the proportion of fenced pastures) in order to assess the effect of overgrazing on dog infection through modification of intermediate host populations.

The other studies focused on landscape-related exposures compared outcomes in various habitats but their designs were too different to form a group for synthesis: Bastien et al. [94] explored the interface between wild and domestic definitive hosts (respectively foxes and cats) and tested the effect on human prevalence; Hegglin et al. [95] compared infection in foxes in different types of habitats (urban, border, and peri-urban habitats); Robardet et al. [96] also studied the infection in foxes along an urbanization gradient, in relation with intermediate host populations.

Group 11 (\% of grasslands): At the exception of Danson et al. [87] and Pleydell et al. [91], the studies were all rated "low validity" for temporal and/or spatial coherence. Results from the two medium/high validity studies $[87,91]$ illustrate how difficult it is to establish a link between landscape and epidemiology, in a disease that has a very long period of latency. Both studies reported contrasted results depending on the type of land-class (intensively grazed grasslands vs. less intensively grazed grass and shrub areas) and on the year of land-use data. Results from these two studies tend to indicate that humans are more infected with Echinococcus multilocularis in landscapes with a high proportion of highly grazed grasslands. However, the impossibility to obtain robust and fine-scale land-use data over 
several decades in the study region (China) prevents the authors from drawing any definitive conclusion. The less valid studies $[35,86,88-90]$ reported a positive correlation between echinococcosis incidence or prevalence and the proportion of grassland in the landscape, but none of them accounted for the latency period of the disease. Thus, results from these studies should be taken with much caution.

\section{Animal biodiversity-related exposures}

The exposures included: density of rodents ([92, 93, 92, 93]; group 12), density of sheep [99], host species richness [90], predation ([100, 101]; group 13). Two studies were excluded from synthesis as they were attributed a medium/low level of validity [93, 97].

Group 12 (density of rodents): Two studies with a medium/low level of validity were excluded from synthesis $[93,97]$. The remaining three studies reach similar conclusions but had different validities. The study conducted by Saitoh et al. [98] had medium or high levels of temporal and spatial replication and coherence. It reported a significant positive correlation between the density of rodents and the infection in definitive hosts (foxes). The two other studies lack methodological coherence, with exposures and outcomes assessed at different sites and/or during different years [92, 96]. Viel et al. [92] also reported a significant positive correlation, this time between the density of rodents and human infection. Robardet et al. [96] reported a significant negative correlation between the abundance of water voles and the optical density measured in the faeces of foxes. This difference with Saitoh et al. [98] could be due to the poor spatial and temporal coherence between exposure and outcome assessment. In particular, authors collected fox faeces on the same transects than those on which the rodent density was estimated. But, given the large hunting area of foxes, rodent density should have been assessed at a larger spatial scale in order to be linked to the optical density in fox faeces.

Group 13 (predation): The two studies in this group were performed by the same research team and were attributed a medium validity as they both lack spatial and temporal replication. Results from these studies should therefore be interpreted with caution even if they reach similar conclusions. Messier et al. [100] found that the infection prevalence in moose was higher in the study area with a high density of wolves than in the areas with a medium and low density of wolves. Joly et al. [101] added that the aggregation of parasites in the moose population was lower in the area of high wolf density. Authors interpreted these results as follows: high predation rates by wolves (a final host for Echinococcosis granulosus) would increase egg contamination within the environment, thus increasing moose infection prevalence in areas of high wolf density. An increased vulnerability to predation of highly infected moose would result in a lower infection aggregation in areas of high wolf density.

\section{Leishmaniasis}

Fifteen studies were retained for this disease (Additional file 5). One study assessed the outcome in the sandfly vector, three in intermediate hosts, ten in humans, two in dogs and humans.

\section{Landscape-related exposures}

Two studies tested the effect of the proportion of forest in the landscape on human incidence $([102,103]$; group 14). Three studies focused on the distance between the villages in which the outcome was measured and the nearest forest ([104-106]; group 15).

Two studies assessed the effect of forest perturbation, with the outcome measured in small mammal hosts [107] or humans [108]. The latter was excluded from validity assessment as it did not include any statistics. One study focused on the effect of habitat perturbation in an arid ecosystem in Israel [109]. Two studies tested the link between vegetation cover, using NDVI as a proxy, and canine and/or human incidence ([110, 111]; group 16). Finally, four studies compared the epidemiological outcome in different habitats, but the diversity ofhabitats studied was too high to form a group for synthesis [109, 112-114].

The three groups were characterized by similar results despite differences in methods and in confidence levels within each group.

Group 14 (\% forest): One of the two studies [103] was attributed a high validity for all four criteria and can thus be considered as highly robust. It reported that the incidence of leishmaniasis in humans was positively correlated with the proportion of forest in the landscape. The remaining study included in this group was attributed a medium/low validity because of a lack of spatial and temporal replication, so its results are not examined here.

Group 15 (proximity to forest): Both Nackers et al. [104] and Chaves et al. [106] are considered as moderately valid because they lack temporal replication. They both reported similar results: the incidence of leishmaniasis in humans would increase with the proximity to the forest. The third study in this group was excluded from synthesis due to a medium/low level of validity [105].

Group 16 (vegetation cover): The two studies differed in their external validity: Neto et al. [110] had a high level of spatial and temporal replication, while Saraiva et al. [111] lacked temporal and to a lesser extent spatial replication. Neither studies reported a link between the 
vegetation cover and human incidence of leishmaniasis in urban areas.

\section{Animal biodiversity-related exposures}

Bellali et al. [115] studied the effect of the density of wild hosts on human incidence. Ghatee [114] investigated the effect of the proximity to cattle, sheep and goats on human incidence. Due to this diversity of exposure no synthesis was attempted.

\section{Leptospirosis}

Leptospirosis is a bacterial disease, mostly transmitted by small mammals and ruminants (mostly cattle), through contact with water contaminated with urine. Five studies were retained for this disease (Additional file 5).

\section{Landscape-related exposures}

No study investigated exposures related to landscapes or habitats.

\section{Animal biodiversity-related exposures}

Derne et al. [116] tested the dilution effect hypothesis on the prevalence in human beings at a global scale. The other studies all tested the effect of wild hosts-related exposures on the infection in wild hosts, but these exposures were very heterogeneous: proximity with fruit bats [117], composition of rat population [118], density of small mammals [119], and density of rodents [120]. As such any synthesis was not attempted.

\section{Lyme disease}

Sixty-four studies were retained for this disease (Additional File 5). They were all conducted in Europe $(n=34)$ or North America $(n=30)$. Half of the studies focused exclusively on variables related to landscapes or habitats, nine looked only at variables related to animal hosts or predators, and twenty-three mixed the two types of approaches.

\section{Landscape-related exposures}

A commonly studied landscape-related exposure was forests. Specifically, many studies tested the effect of the proportion of forest in the landscape $(n=8)$, the fragmentation of forests $(n=6)$, the type of forest $(n=13)$, and the vegetation cover on the forest ground $(n=14)$.

In the eight studies that tested the effect of the percentage of forest in the landscape (group 17), the outcome was measured only in ticks $(\mathrm{n}=4)$, only in humans $(\mathrm{n}=3)$, or in both ticks and humans $(\mathrm{n}=1)$.

Six studies tested the effect of forest fragmentation (group 18) on tick [23, 40, 121-123] and human infection $[123,124]$. Three types of vegetation were included in the retained studies: forests, bushes in forests, and groundcovering vegetation (grass, moss, etc.).

Trees: The effect of the type of forest on the disease was tested in thirteen studies. One of them [125] presented analyses that were also part of a larger study [126]. Another was designed to test the interaction between the type of forest and grazing by cattle and did not test for an effect of the type of forest alone [127]. Lynn et al. [128] and Eisen et al. [129] tested differences between types of forests that are very particular to California and could not be classified as either deciduous or coniferous forests, which was the classification used in all the other studies. We thus excluded these four studies from validity assessment, resulting in a group of nine studies (group 19). These studies all aimed to test whether deciduous forests, considered as richer in term of biodiversity and more favorable to intermediate hosts of Borrelia, differed from coniferous forests with regards to Borrelia infection. In all of these studies, the outcome was assessed in ticks (e.g. prevalence of infection and/or density of infected ticks), but never in intermediate hosts or humans. The types of forest that were compared were deciduous, coniferous, and sometimes mixed-type forests. Two other studies tested the effect of forest density [130], and one the percentage of canopy cover [131].

Bushes: In six studies, the variable "type of forest" was combined to a variable "presence/absence of a shrub cover", in order to separate the effect of the shrub cover, known to be a suitable habitat for ticks. As for the "type of forest" group, we excluded one study [125] as it presented analyses that were also part of a larger study included in the validity analysis [126]. Three other studies focused on the invasive bush Berberis and tested the effectiveness of various control methods on tick populations and infection rate [43-45]. These 3 studies are related to the same long-term experimentation, two of them presenting intermediate results and the third one presenting the final results. To avoid any redundancy, we only included the final publication [45] in the validity assessment, resulting in a group of six studies (group 20).

Ground-covering vegetation: In four studies, the nature of the vegetation cover (i.e. herbaceous, ericaceous, moss etc.) on the forest ground was categorized and tested in addition to the type of forest [127, 132-134]. However, the vegetation categories differed between studies, preventing the formation of a group for synthesis. Two studies tested the percentage of area covered by grass [127, 135], the other tested the density of the grass cover [136].

Differences in Borrelia infection between habitats were tested in 13 studies. All of them looked at the effect of habitat type on Borrelia infection in ticks, and 2 also measured the prevalence in intermediate hosts. However, these 13 studies could not form a group for synthesis, 
given that the combination of the habitats that were compared was quite unique to each study.

Eight studies were excluded from the synthesis as they did not present any statistical tests to consolidate their results [40-42] or were of medium/low validity [121, 137-140]. Two studies [121, 133] were attributed a medium/low validity for the parts specific to rodent and/ or deer densities. They were thus excluded from these parts of the synthesis.

Group 17 (\% of forest): The two studies that looked at the relationship between the proportion of forest in the landscape and the infection in humans reported an absence of correlation between these two variables [46, 124]. However, they could not be considered as highly valid. One had a robust spatial coherence between exposure and outcome (the locality of the tick bite is known) but lacked information regarding temporal coherence [46]. The other had a robust temporal coherence between exposure and outcome (very recent land-use data) but a poor spatial coherence (the place of tick bite is not known, and the residential address of patient is used to localize the cases) [124]. The two other studies investigated the relationship between the proportion of forest in the landscape and the density and infection of ticks $[141,142]$. Both studies weree robust in terms of spatial coherence and replication, but they both lacked temporal coherence and/or replication (medium validity). They reported an absence of correlation between the proportion of forest in the landscape and the density of ticks [141], the tick load of deers [142], or the prevalence of infection in ticks $[141,142]$.

Group 18 (forest fragmentation): The two studies that tested the effect of forest fragmentation on human incidence were attributed a medium validity [123, 124]. Their main limit wass that they georeferenced the human cases of Lyme Disease based on the residential address of patients and not on the place of tick bites, which wass not known. Given this major limit, it is very difficult to interpret the contrasted results they reported: an absence of correlation between forest fragmentation and human incidence in Seukep et al. [124] and a significant negative correlation in Brownstein et al. [123].

The studies that assessed the outcome in ticks are considered as moderately valid, as they rely on a single year of data for Outcome [23, 121-123]. Moreover, they used different variables to characterize forest fragmentation, which might in part explain the variability in the results they report: a positive correlation between forest fragmentation and tick density and/or infection prevalence [23, 121-123], a negative correlation [122], or no correlation [124]. Overall, our ability to draw conclusions from these studies is limited for two reasons: the lack of temporal replication and the high heterogeneity in the type of variable used to characterize forest fragmentation.

Group 19 (type of forest): Among the nine studies that compared different types of forests, four were attributed a medium/high validity. These four studies reported similar results: a higher density of nymphs infected with Borrelia burgdorferi s.l (i.e. one of the major risk factors for human infection with Lyme disease) in deciduous or mixed-type forests than in coniferous forests [126, 132, 133, 143]. Among the studies with a medium validity, the results were contrasted. Some reported a higher density of ticks in deciduous or mixed-type forests [144, 145] while others found no difference in the density of ticks in deciduous and coniferous forest [146, 147]. It is interesting to note that the studies that did not find a positive correlation between the type of forest and the density of ticks were based on a single year of data. This absence of temporal replication might have prevented the authors from identifying a potential correlation, for example if the sampling was performed during a dry year (with a dry litter in deciduous forests, thus unfavorable to ticks).

Group 20 (presence/absence of bushes): All the studies that tested the effect of bushes on tick populations and tick infection drew the same conclusion: the presence of bushes on the forest ground increased the density of all stages of ticks $[126,134,143,145]$, which resulted in an increased density of infected ticks [117, 140, medium/ high confidence level], although the prevalence of infection did not differ between forests with and without bushes $[47,126,134,143,145]$. However, one of the two studies with a temporal replication found that this result was not consistent over the years [126], suggesting a possible interaction with climatic variables. Williams et al. ([45], medium/high validity) tested experimentally the effect of clearing the bushes and concluded that it resulted in a decreased tick density, a result shared by Hubálek et al. [47], mediumvalidity. This last study found that this effect became less pronounced 2 to 3 years after the clearing.

\section{Animal biodiversity-related exposures}

The effect of wild hosts density on Borrelia infection was tested in 21 studies. These studies were split into two groups for validity assessment, based on the roles played in the epidemiological cycle with small mammals in one group ( $n=13$, group 21$)$, and cervids in the other $(n=18$, group 22)., Among the 13 studies investigating the density of rodents/small mammals, 9 measured the outcome only in ticks, 2 only in mice, 1 only in humans, and 1 in ticks and humans. Among the 18 studies with deer density, 14 measured the outcome only in ticks, 2 only in humans, and 2 in ticks and humans. The effect of wild host species richness was tested in 7 studies (group 23). 
The outcome was mostly assessed in ticks, at the exception of Linske et al. [148] that measured the outcome only in mice. Two studies measured also the outcome in humans [46] or in small mammals [136]. Two studies investigated the effect of predation on Lyme disease (group 24) with very different approaches: Levi et al. [32] studied the effect of coyote and fox abundance on human incidence of disease, while Ostfeld et al. [42] tested the effect of the composition of the predator community on the infection in ticks.

Group 21 (density of rodents): The density of rodents at year $n-1$ had no effect on the human incidence of Lyme disease in Mysterud et al. [46]. For rodents, the result varied depending on the species in which the outcome was assessed: no effect of rodent density at year $n$ on the seroprevalence in bank voles (Myodes glareolus) [149] and white-footed mice (Peromyscus leucopus) [150], but negative effect in wood mice (Apodemus sylvaticus) [149].

The density of rodents at year $n-1$ was positively linked to the density of infected ticks in the four studies that were attributed a medium/high validity [42, 46, 148, 151]. This effect was mediated by a positive effect on tick density ([42, 148, 151], medium/high validity) and/or infection prevalence $[46,148]$. The studies that assessed rodent density and tick infection during the same year, and thus did not account for the expected delayed effect due to the biological cycle of the Ixodes tick, all reported an absence of correlation between the density of small mammals and the density of infected nymphs ([131, 138, $149,152]$, medium validity).

Group 22 (density of cervids): Four studies were excluded from the synthesis as they were attributed a medium/low validity $[120,133,138,139]$. The three studies that tested the effect of deer density on the human incidence of Lyme disease found a positive correlation, but variable in time and in space. Mysterud et al. [46] and Levi et al. [32] both found positive temporal and spatial correlations between deer density at year $n-1$ and the incidence of Lyme disease, but not in all the regions or states studied. This suggests that the link between deer density and the human incidence of Lyme disease was affected by other factors that varied geographically. Andersen et al. [48] conducted a study at the scale of the Funen Island (Denmark) and found a positive correlation between the density of roe deer at years $n-3$ and $n-2$ and human incidence. Authors did not detect any correlation when using the density of roe deer at years $n-1$ and $n$.

Five studies found an increase in tick density with increasing deer density at year $n[131,132,146]$, or $n-1$ [46]. However, results regarding the prevalence of infection in ticks were much more heterogeneous, with positive correlations ([132] for red deer), negative correlations $[46,153]$ or absence of correlation $([131,132]$ for roe deer, [146]). Two studies reported an absence of correlation between deer density (at year $n$ in [147], at year $n$-2 in [152]) and tick density or prevalence of infection.

Group 23 (host species richness): The only study with a medium/high validity found no link between host species richness and the infection in humans [46]. The other studies were attributed a medium validity and also reported an absence of link between host species richness and density/infection in ticks $[125,138]$, and seroprevalence in small mammals $[136,150]$. One study [131] found that rodent species richness had a negative effect on the density of nymphs, their infection prevalence, and in fine the density of infected nymphs, but only when the relative abundance of Peromyscus mice in the rodent community was high. This apparent contradiction between the results obtained by Bouchard et al. [138] and Werden et al. [131] could be due to the fact that, in the experiment led by Bouchard et al., the abundance of Peromyscus mice increased with rodent species richness, while Werden et al. had access to sites with a high rodent species richness and a low relative abundance of Peromyscus mice, which allowed to disentangle the two variables.

Group 24 (predation): The study with the highest validity [32] reported positive temporal and spatial correlations between Lyme Disease cases and coyote abundance, and negative correlations between Lyme Disease cases and fox abundance. Results from Ostfeld ([42], medium validity) were coherent with this result: the authors found that the prevalence of infection in ticks was significantly lower in sites with the most functionally diverse predator assemblages and higher in sites where coyotes displaced some or all of these predators.

\section{Malaria}

Malaria is caused by several species of the genus Plasmodium, a protozoan transmitted by anopheline mosquitoes. Because of their importance in the ecology of the Anopheles vector, two types of land-use classes were particularly studied: forests (including deforestation) and waterbodies. Overall, 29 relevant studies were retrieved for this disease (Additional file 5).

\section{Landscape-related exposures}

The effect of the proportion of forest in the landscape was assessed on vector [153] or human [76, 154-156] infection (group 25). Studies focusing on deforestation were very heterogeneous in the type of exposure they assessed: rate of forest loss [157], percentage of forest cover lost during the past year and the past 5 years [154], comparison between stages of forest [158], percentage of 4 stages of forest indicating deforestation [159]. One study tested 
the effect of the distance to the nearest forest [160] and two studies compared epidemiology in dense forest and in other habitats (fringe forest [161]; villages [162]). The effect of the proportion of waterbodies was tested in five studies that were highly heterogeneous in the type of waterbody included: all types of temporary and permanent waterbodies [76], irrigated rice fields [163], fish ponds [164], streams [156], deep water bodies [165]. This was also the case of the four studies testing the effect of the distance to the nearest waterbody [156, 165-167].

Five studies compared different habitats with a high variability between studies (different types of savannas, of forests, of aquatic habitats etc.). Four other studies compared different types of agro-ecosystems to test for an effect of irrigation on human incidence $(\mathrm{n}=2)$ and/ or vector infection $(n=3)([168-171]$, group 26$)$. Haque et al. [172] was the only study looking at the effect of NDVI, as a proxy for climate.

Group 25 (\% of forest): One study was attributed a medium/low validity and excluded from synthesis [76]. The three studies with a medium/high validity reported a human incidence increasing with the proportion of forest around villages [154-156]. Lainhart et al. [153], who was attributed a medium validity due to a lack of spatial and temporal replication, also reported an increasing proportion of infected mosquitoes and an increased Human Biting Rate with the proportion of forest around villages.

Group 26 (type of agroecosystem): The four studies that compared different types of irrigated and non-irrigated agroecosystems were very similar in terms of validity (medium) and study design but reported contrasted results. Both Jaleta et al. [168] and Mboera [171] reported a higher entomological infection rate (i.e. mean number of infected bites per night) and/or human prevalence in irrigated agroecosystems (respectively sugarcane and rice) that in the non-irrigated traditional agroecosystem. An opposite result was found by Ljumba et al. [169, 170], who reported that, although there was less vectors in the non-irrigated traditional agroecosystem, they were much more often infected, resulting in a higher entomological infection rate and in a higher human prevalence. However, the authors of these two studies mentioned the presence of a dam near the non-irrigated traditional agroecosystem, that could have affected the result.

\section{Animal biodiversity-related exposures}

Only two studies assessed exposures related to animal biodiversity: Fuller et al. [173] tested the effect of the diversity of vector species on human incidence. Roux et al. [174] tested the effect of predation of the mosquito vector on mosquito infection.

\section{Schistosomiasis}

Schistosomiasis is caused by a parasite from the genus Schistosomia sp., whose obligatory intermediate host is an aquatic mollusc. The infection happens through contact with water contaminated by Schistosomia cercariae. Nine studies were retained for this disease (Additional file 5). Three types of exposures were found in those studies: predation $[175,176]$, host species richness [30, 177], and vegetation cover [178-180]. Among them, two studies investigated initially the effect of non-eligible interventions (dams and pesticide use). However, they were retained during the screening process because they also contained data on an eligible intermediate exposure: predation $[49,181]$.

\section{Landscape-related exposures}

Three studies looked at the vegetation cover around waterbodies (group 27): Klumpp et al. [180] studied the effect of an aquatic weed on the density of intermediate hosts and on an epidemiological index in humans; Simoonga et al. [179] tested the effect of NDVI (index of greenness) on human prevalence, as did $\mathrm{Hu}$ et al. [178] along with other variables related to landscape composition (proportions of various land-uses and distance to the Yang-Tse river).

Group 27 (vegetation cover): One of the studies [179] was attributed a medium/low validity and is not discussed here. The two remaining studies have a high level of temporal and spatial coherence and are considered as robust, although they lack temporal replication [178, 180]. Klumpp et al. [180] found a positive correlation between the vegetation cover in or around waterbodies and infection in humans, through an increase in the density of the intermediate host. Hu et al. also reported a positive relationship between schistosomiasis and NDVI, but authors reported it as weak in comparison to other more important factors such as the proximity to the river.

\section{Animal biodiversity-related exposures}

Four studies tested the effect of predation on schistosomiasis, with an outcome measured either in humans $[175,176]$ or in intermediate hosts $[49,181]$ (group 28). Stauffer et al. [175] and Diakité et al. [176] both looked at the correlation between predator density and human prevalence in the field, while Halstead et al. [49] tested experimentally the effect of pesticides on the density of infected intermediate hosts, through modifications of predator densities and vegetation in a mesocosm. Sokolow et al. [181] compared changes in human prevalence of schistosomiasis due to dam construction on rivers inside and outside the historical distribution zone of prawns. Two studies aimed to test the "dilution effect" hypothesis (group 29): Johnson et al. [30] performed an 
experiment in a mesocosm and measured the outcome in intermediate hosts, while Stensgaard et al. [177] measured host species richness in the field and tested the effect on human infection.

Group 28 (predation): Halstead et al. [49] conducted an experiment in mesocosms that was attributed the highest level of validity for all four criteria. Authors found that, in mesocosms, the density of predators was negatively correlated to the density of infected intermediate hosts. This effect was driven by a change in the density of intermediate hosts, but not of their prevalence of infection. Stauffer et al. [175] lacked temporal replication but can still be considered as highly? valid because of a good spatial and temporal coherence in the assessment of exposure and outcome. It reported a significant negative correlation between the density of molluscivorous fish and human prevalence. Diakité et al. [176] was close to Stauffer et al. [175] in terms of validity. It also reported a negative correlation between the presence/density of predatory prawns and the density of intermediate hosts but did not find any relationship with the human prevalence of schistosomiasis. Sokolow et al. [181] was considered as the least valid of the group, because it used exposure data from the literature and not from the field and lacked information regarding replication. However, results from this study tend to support those of Stauffer et al. [175]: the construction of dams, that perturbates riverine prawns, led to a higher increase in human prevalence inside areas of historical prawn distribution than outside.

Group 29 (host species richness/diversity): The study in mesocosms from Johnson et al. [30] received the highest level of validity for all criteria. Authors found that increasing host species richness decreased the prevalence intensity of infection in intermediate hosts. Stensgaard et al. [177] is considered as less valid because the exposure and the outcome were assessed in different studies (different sites and years). It reported a significant negative correlation between host species richness and human prevalence. However, this correlation disappeared when a spatial component was introduced in the model, suggesting a high autocorrelation between sampling points.

\section{West Nile fever}

West Nile fever is a mosquito-borne disease that is caused by a virus (West Nile Virus) and maintained in nature through infection cycles involving avian hosts and mosquitoes. It can affect a large range of dead-end hosts, such as human beings and equines. The hypothesis is that the composition and structure of landscapes is linked to the abundance of Culex vectors and bird hosts, and to the composition of bird communities (species richness, identity of species etc.). All of this could modify the risk of infection in Culex vectors, birds and humans. Twentysix studies were retained for this disease (Additional file 5). The majority $(n=15)$ exclusively focused on landscape/habitat-related exposures. Eight focused on avian hosts-related exposures, and three studied both types of exposures. The type of outcome measured was highly heterogeneous, with some studies measuring epidemiological variables only in vectors $(n=7)$, only in avian hosts $(n=5)$, only in humans $(n=5)$, in vectors and avian hosts $(n=2)$, in vectors and humans $(n=5)$, in avian hosts and humans $(n=1)$, or in vectors, avian hosts and humans $(\mathrm{n}=2)$.

\section{Landscape-related exposures}

Among the 18 studies that tested the link between landscape- or habitat-related variables on West Nile disease, a majority $(n=13)$ used landscape composition variables as exposures, such as the percentage of urban areas $(n=7)$, of forests $(n=8)$, or of wetlands $(n=7)$ in the landscape (respectively groups 30,31 and 32 ). The correlation with the structure of the landscape was tested in four studies that respectively studied landscape heterogeneity [182], landscape fragmentation [183], mean size of forest patches [184], and mean wetland size [185] as exposures. Three studies compared mosquito infection in different types of habitat or micro-habitat [186-188]. Three studies focused on variables linked to vegetation cover: type of forest and structure of vegetation cover [184], vegetation density with measure of NDVI [189] and presence of two invasive aquatic macrophytes [190]. Two studies were discarded from synthesis due to a very low prevalence of WNV infection at the time of observation $[191,192]$.

Group 30 (\% of urban areas): Three global studies were of medium/high validity and another three of medium validity. All of them have a medium to low temporal validity, and many (75\%) have a low temporal coherence. Results are variable across studies. Correlations between urban land use and seroprevalence in birds were not supported by correlations between mosquitoes and prevalence in human beings. This may be linked to differences in the vector species observed in these studies: Culex tarsalis, in DeGroote et al. [193], is found in rural habitats whilst Culex pipiens and Culex quinquefasciatus in LaBeaud [183] and Lockaby [184] prefered urban areas whereas Culex salinarius, in Ezenwa et al. [194], was mostly found in salt marshes.

Group 31 (\% of forest): The four studies with the highest global validity $[184,193,195,196]$ had a spatial validity but often lack strong temporal validity. These four studies do not study the same hosts (mosquitoes or birds) and obtained variable results even when taking the type of host into consideration. The four Medium validity 
studies also found variable results [183, 189, 194, 197]. The only study observing a negative correlation between \%forest and bird infection was also the one that has the lowest validity, the others did not report significant correlations. There may be an impact on the level of temporal replication as, independent from the general confidence level, it seems that studies having observed a significant correlation are those for which observations were at least conducted for 3 years (Additional file 4).

Group 32 (\% of wetlands): Two out of five studies were of medium/high validity, and obtained divergent results (De Groote et al. [193], Gibbs et al. [196]). All the medium validity studies found a significant correlation but it is difficult to draw any conclusion or hypothesis as they widely vary in spatial and temporal robustness. There could be a trend towards a potential negative correlation between infection of humans $([185,193]$ only in counties dominated by Culex pipens and Culex restuans, but not Culex tarsalis) or mosquitoes [194] and wetlands or open water [183] but the reason why Gibbs et al. [196] do not obtain similar outcomes remains unclear.

\section{Animal biodiversity-related exposures}

Eight studies investigated the "dilution effect" hypothesis, by testing the effect of avian species richness on the infection in vectors [188], avian hosts [198], humans $[199,200]$, vectors and avian hosts $[186,201]$, or vector and humans [202, 203] (group 33). Four studies investigated the effect of community composition on infection ([200, 201, 200, 201], group 34). Three studies looked both at the dilution effect and the community composition to test which one was more linked to the epidemiology of West Nile disease [200, 201, 203].

Group 33 (avian species richness/diversity): The three studies with a high/medium validity were considered of higher quality mostly due to their temporal coherence and none of them observed a significant correlation between avian species richness and mosquito or human infection by WNV. Discarding one study (205b) because of a medium/low validity, the remaining medium validity studies all reported significant negative correlations between species richness or diversity and infection rates. Regarding Levine et al. [186] and Ewenza et al. [202], correlations were significant or not depending on the composition of the avian sample. It is difficult to provide any suggestion explaining how less valid studies reach significant correlations compared to more valid ones.

Group 34 (host community composition): Studies in this group were of variable validity, with low validity in spatial coherence and temporal replication for many of them. The best study based on spatial and temporal coherence and replication levels is that of Reisen et al. [204], who did not find any significant correlation between infection rates and bird community composition, although the study only took place only over 1 year. The two other medium/high validity studies either did not find any significant correlation between host community composition and infection [201] or highlighted that the abundance of amplification birds seem to be a better predictor of infection than bird richness or diversity [200]. The two other studies [205a \& b] of medium/low validity are not discussed.

\section{Zika}

Our bibliographic search did not allow to find any relevant studies for this disease.

\section{Reasons for variability}

Our systematic map highlighted variable results in 16 "disease x exposure" groups (cf. Table 2). In 15 groups the studies reached similar conclusions but they should be considered with caution due to the small number studies and the variation in their validity Variable results were found for avian influenza, bovine tuberculosis, Lyme disease and West Nile disease. Several hypotheses might explain such disease specificvariability,: (1) different species were sampled, suggesting spatial differences in the ecology of the disease: for West Nile, different Culex species were found depending on the study area, and for Lyme disease, various rodent and deer species were sampled in the different studies, (2) differences in the way the exposure was assessed or characterized (e.g. different variables used for forest fragmentation, species richness calculated in different groups), and (3) differences in the length of studies: this was the case for studies investigating the effect of rodent density on Lyme disease. All the studies reporting an absence of correlation were 1-year long studies in which rodents and ticks were sampled within during the same year $[131,138,149,152]$, while all the studies that did report significant correlation sampled ticks 1 year after rodents to take into account the pluriannual biological cycle of ticks [42, 46, 148, 151]. We expected such a difference between shorter and longer studies to be more observed for diseases involving vectors and/or hosts with a complex life-cycle. However, the studies conducted for a short period of time (from one to a few years) are susceptible toy interannual variations in climate, population dynamics, food resources (etc.). They are more likely to display a range of results reflecting the very specific conditions of the year of the study.

Regarding human epidemiological data, differences in the reporting of cases of infection could create variation among results from different countries, although it was impossible to assess this hypothesis during this review. For instance, for Lyme disease, reporting infection is 
Table 2 Summary of findings for the 34 groups of articles screened according to their validity

\begin{tabular}{|c|c|c|c|c|c|}
\hline Disease & Group number & Exposure & $\begin{array}{l}\text { Number of studies } \\
\text { synthesized }\end{array}$ & Findings & $\begin{array}{l}\text { Result } \\
\text { sub- } \\
\text { section }\end{array}$ \\
\hline \multirow[t]{5}{*}{ Avian Influenza } & 1 & $\%$ of riceland & 4 & Variable & 1.1 \\
\hline & 2 & $\%$ of waterbodies & 7 & Variable & 1.1 \\
\hline & 3 & Distance to waterbodies & 3 & Variable & 1.1 \\
\hline & 4 & Vegetation cover & 4 & Variable & 1.1 \\
\hline & 5 & Contact with wildlife & 2 & Similar & 1.2 \\
\hline \multirow[t]{4}{*}{ Bovine tuberculosis } & 6 & $\%$ of grasslands & 2 & Variable & 2.1 \\
\hline & 7 & $\%$ of forest & 2 & Variable & 2.1 \\
\hline & 8 & Host species richness & 3 & Variable & 2.2 \\
\hline & 9 & Contact with wildlife & 2 & Variable & 2.2 \\
\hline Brucellosis & No group & & & & 3 \\
\hline Chikungunya & No group & & & & 4 \\
\hline Cryptosporidiosis & No group & & & & 5 \\
\hline Dengue & 10 & $\%$ of urban land-use & & Similar & 6.1 \\
\hline \multirow[t]{3}{*}{ Echinococcosis } & 11 & $\%$ of grasslands & 8 & Similar & 7.1 \\
\hline & 12 & Rodent density & 3 & Similar & 7.2 \\
\hline & 13 & Predation & 2 & Similar & 7.2 \\
\hline \multirow[t]{3}{*}{ Leishmaniasis } & 14 & $\%$ of forest & 1 & Similar & 8.1 \\
\hline & 15 & Distance to forest & 3 & Similar & 8.1 \\
\hline & 15 & Vegetation cover & 3 & Similar & 8.1 \\
\hline Leptospirosis & No group & & & & 9 \\
\hline \multirow[t]{8}{*}{ Lyme } & 17 & $\%$ of forest & 4 & Similar & 10.1 \\
\hline & 18 & Fragmentation of forests & 5 & Variable & 10.1 \\
\hline & 19 & Type of forest & 9 & Variable & 10.1 \\
\hline & 20 & Presence/absence of shrubs & 6 & Similar & 10.1 \\
\hline & 21 & Density of rodents & 9 & Variable & 10.2 \\
\hline & 22 & Density of cervids & 12 & Variable & 10.2 \\
\hline & 23 & Host species richness & 6 & Variable & 10.2 \\
\hline & 24 & Predation & 2 & Similar & 10.2 \\
\hline \multirow[t]{2}{*}{ Malaria } & 25 & $\%$ of forest & 4 & Similar & 11.1 \\
\hline & 26 & Type of agroecosystem & 4 & Variable & 11.1 \\
\hline \multirow[t]{3}{*}{ Schistosomiasis } & 27 & Vegetation cover & 4 & Similar & 12.1 \\
\hline & 28 & Predation & 2 & Similar & 12.2 \\
\hline & 29 & Host species richness & 3 & Similar & 12.2 \\
\hline \multirow[t]{5}{*}{ West Nile } & 30 & $\%$ of urban land-use & 6 & Variable & 13.1 \\
\hline & 31 & $\%$ of forest & 8 & Variable & 13.1 \\
\hline & 32 & $\%$ of waterbodies & 5 & Variable & 13.1 \\
\hline & 33 & Host species richness & 8 & Variable & 13.2 \\
\hline & 34 & Host community composition & 4 & Variable & 13.2 \\
\hline
\end{tabular}

mandatory in Norway [46], but not in most European countries.

\section{Limitations}

\section{Limitations in our methodology}

During the screening process, we excluded studies implying culling campaigns. This choice was made by the stakeholders but might have resulted in the exclusion of studies that could have been compared with studies that investigated the effect of host density. This was also the case for studies on fences, that were not considered eligible and excluded during screening.

One of our main inclusion criteria was the presence of an epidemiological measure, whether in vector, animal host, or human. This criterion led us to exclude studies 
that would have tested links between landscape- or biodiversity-related exposures and vector or animal host populations of interest for the diseases included in this review. Performing a review of literature on this aspect could be highly complementary with our work, especially for mosquito-borne diseases on which we found very few relevant articles which included variables related to both biodiversity and epidemiology.

We were not able to find the reprints of 95 articles that were initially identified by the searches and screened at title and abstract as relevant. The list is provided in Additional file 4 and should help upgrading this map. Given the rejection rate at full text, this may have only added one or two studies in some groups, but this could nevertheless seriously impact the analyses we initiated, given the small number of studies for each disease. Moreover, we could not search for literature in Spanish and Portuguese, although there might be relevant studies for some diseases such as leishmaniasis and schistosomiasis that are major public health issues in South America and in the Caribbean islands. Due to time-constraints, we excluded 92 studies that addressed unique "disease $\mathrm{x}$ exposure" combinations from validity assessment and the subsequent map. If their validity was high enough, including external validity, they could nevertheless be of interest. Finally, we excluded articles in which the authors only reported observational results without data or data with no statistical analysis. Although not clearly reported by the authors, this may have been due to non-significant analysis. Such articles could nevertheless be used if a meta-analysis were to be conducted when the number of studies is sufficient.

[Please insert here Fig. 4, with following caption: "Fig. 4: Number of articles for each "disease $x$ exposure" combination"].

\section{Limitations of the evidence base}

We identified major knowledge gaps (cf. Figure 4), with no relevant articles for Zika, and only two articles on biodiversity-related exposures for mosquito-borne diseases (malaria, dengue and Chikungunya). Indeed, for several diseases including major vector-borne diseases such as malaria, dengue or leishmaniasis, the studies retained in this review focused exclusively on landscape or habitatrelated exposures, but seemingly no research regarding the links between biodiversity-related functions (e.g. vector predation, competition between mosquito species, etc.) and these diseases.

Although stakeholders were interested by operational management, very few interventions focused on

\begin{tabular}{|c|c|c|c|c|c|c|c|c|c|c|c|c|c|c|c|}
\hline \multicolumn{8}{|c|}{ Vector-borne diseases } & \multicolumn{6}{|c|}{ Non vector-borne zoonoses } & : & \multirow{5}{*}{ 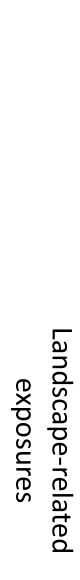 } \\
\hline & 2 & 2 & 3 & & 2 & 11 & 3 & & 1 & & & & 3 & \multirow{4}{*}{$\begin{array}{l}\text { Vegetation cover } \\
\text { Habitat perturbation } \\
\text { Type of habitat } \\
\text { Landscape composition }\end{array}$} & \\
\hline & 1 & 4 & & & 3 & & & & & & & & & & \\
\hline 1 & 1 & 11 & 3 & & 4 & 13 & & & 1 & & 3 & & & & \\
\hline 1 & 3 & 13 & 14 & & 5 & 26 & 10 & 4 & 1 & & 10 & & 1 & & \\
\hline & & & & & 1 & 21 & & 4 & 4 & 3 & 6 & 2 & 5 & Host density & \\
\hline & & & 6 & & & 7 & 1 & & & & & 1 & & Community composition & (]) \\
\hline & & 1 & 8 & & & 7 & & 3 & & 1 & 1 & 1 & 2 & Species richness/diversity & 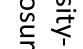 \\
\hline & & 1 & & & & 2 & & & & & 2 & & 4 & Predation & $\stackrel{\overrightarrow{0}}{\mathbb{D}}$ \\
\hline & & & & & & & 2 & 3 & 2 & & 1 & 1 & & Contact with wildlife & \\
\hline
\end{tabular}


ecosystem or habitat management, and many studies rather described land-use and landscape composition which did not give precise pathways for interventions. Moreover, among relevant studies, most of them reported correlations between exposure and outcome. Only eight conducted controlled experimentations (two deer exclosure experiments $[46,48]$, two mesocosm experiments $[30,49]$, four field studies with vegetation control [43$45,47])$. This highlights how difficult it may be to conduct before-after controlled experiments when no direct intervention can occur on hosts or vectors, especially when of small size and highly mobile such as rodents or mosquitoes.

The need for medium- and long-term studies, with several inter-seasonal replications, is highlighted to improve the evidence-base. Too many studies are based on a single year of data collection, while seasonal and interannual variations are known to be very high in most vectorborne and zoonotic diseases.

There is also a need for more studies in a variety of ecosystems. For instance, regarding West Nile Disease, all relevant studies were performed in North America, with specific viral strains that hinder any extrapolation to other countries. Conducting such studies in France would be of high interest, and for other diseases as well, in order to see whether the results already obtained are confirmed when studying different ecological communities.

Another limitation concerns human epidemiological data. For several diseases, such as echinococcosis or Lyme disease, it is very difficult to identify the date and place of contamination, making any link with the ecosystem hard to establish. For these diseases, it may be preferable to study the relationships between ecosystems and major risk factors that are easier to monitor (e.g. density of infected vectors or hosts).

\section{Conclusions}

Our review showed that the study of the links between ecosystems and human infectious diseases is still understudied. The vast majority of existing studies uses posthoc correlations based on in situ observations, and there are extremely few experimental designs, due to the ecological complexity of the subject. We were able to highlight major knowledge gaps (mostly concerning biodiversity-related functions such as predation, competition and to a lesser extent dilution/amplification effects) and formulated recommendations for future research.

\section{Implication for policy/management}

There is a growing demand, expressed by stakeholders and by a part of the society, to replace practices that are seen as detrimental to biodiversity (e.g. culling, habitat destruction) by new ones that would integrate biodiversity (e.g. ecological control of populations, habitat management). In order to regulate infectious diseases, two main aspects linked to biodiversity protection or management could be mobilized by policymakers and environmental agencies, should there be scientific evidence that they are efficient: (1) increasing biodiversity (species richness and diversity) by protecting habitats and species, and (2) support predation through predator protection, end of culling or reintroduction of predators. Assessing the regulatory role of these two aspects on infectious diseases is a mandatory first-step towards their integration in health policies. We were able to assess the links between species richness and diseases for four of them (bovine tuberculosis, Lyme disease, schistosomiasis, West Nile disease), but collated very few studies for each disease (respectively $3,7,2,8)$. These studies were highly variable in their results. There is, to date, no evidence of a clear positive relationship between a high biodiversity in host communities and the regulation of certain infectious diseases. As for predation, its potentially protective role on human health was only examined for schistosomiasis (4 studies), and to a lesser extent echinococcosis (2 studies) and Lyme (2 studies). This very small number of articles limits our ability to draw any conclusion. Nevertheless, existing evidence suggests a potential role of predation that should be further investigated.

\section{Implication for research}

Almost all studies investigated correlations between ecosystem-related exposures and epidemiological outcome. Experimentation involving manipulation of animal communities in mesocosms [30,49] or in field plots with the presence of control plots [44-46, 48], are extremely rare and should be encouraged in order to study causal relationships between ecosystem components and epidemiological variables. Long-term field studies should be conducted in order to simultaneously address two issues: (1) to integrate the inter-seasonal and inter-annual variability due to the interaction between pathogens, vectors and/or animal host populations, and climatic conditions, (2) to allow to test for a delayed effect of exposure on epidemiological variables, as in the case of Lyme disease. Finally, researchers should explore the connections linking several diseases that share species involved in their cycle (e.g. foxes that could potentially regulate rodent hosts populations and reduce risks of Lyme disease, but could amplify risks for echinococcosis).

\section{Supplementary Information}

The online version contains supplementary material available at https://doi. org/10.1186/s13750-021-00220-4. 


\section{Additional file 1. ROSES form}

Additional file 2. Results of the bibliographic search and screening of articles for each one of the 14 diseases

Additional file 3. Tests related to the screening of titles and abstract, and Kappa scores

Additional file 4. Lists of articles rejected at full-text and articles for which the full-text was not found (worksheet 1), and articles excluded from study validity assessment because of a unique "disease x exposure" combination (worksheet 2)

Additional file 5. Description of studies included in the systematic map (worksheet 1) and validity assessment (worksheet 2)

\section{Acknowledgements}

The authors would like to thank the peer-reviewers and editors for their useful comments. Many thanks are due to Will Ovenden for improving the English language of the final version. LL thanks the expert group for their regular contribution to this work, and the stakeholder group for useful comments during the planning and scoping stages of this review.

\section{Authors' contributions}

$L L, L A B$ and $B L$ performed the bibliographic search, the screening of articles and the critical appraisal. LL wrote the manuscript, that was corrected by all co-authors. LL and BL amended the manuscript after peer-review and editor's recommendations. All authors read and approved the final manuscript.

\section{Funding}

This review was funded by the French Ministry for Ecological and Inclusive Transition within the framework of the 3rd National Action Plan for Health and the Environment (PNSE3).

\section{Availability of data and materials}

Not applicable.

\section{Declarations}

\section{Ethics approval and consent to participate}

Not applicable.

\section{Consent for publication}

Not applicable.

\section{Competing interests}

The authors declare that they have no competing interests.

\section{Author details}

${ }^{1}$ Fondation Pour La Recherche Sur La Biodiversité, Paris, France. ${ }^{2}$ Institut Des Sciences de L'Evolution de Montpellier, CNRS-IRD-Université de Montpellier, Montpellier, France. ${ }^{3}$ Agence Française Pour La Biodiversité, Vincennes, France. ${ }^{4}$ ANSES, Laboratoire de La Rage Et de La Faune Sauvage de Nancy, Malzéville, France. ${ }^{5}$ Université de Strasbourg, Strasbourg, France. ${ }^{6}$ Parc National Des Ecrins, Grenoble, France. ${ }^{7}$ Animal Et Gestion Intégrée Des Risques, CIRAD, Montpellier, France. ${ }^{8}$ VetAgro Sup, Lyon, France. ${ }^{9}$ mEpiLab, Massey University, Palmerston North, New Zealand. ${ }^{10} \mathrm{CIRAD}$, UMR ASTRE, Guadeloupe, France. ${ }^{11}$ BIOEPAR, INRA, ONIRIS, Nantes, France. ${ }^{12}$ MIVEGEC, IRD-CNRS, Université de Montpellier, Montpellier, France.

Received: 22 January 2020 Accepted: 5 March 2021

Published online: 29 April 2021

\section{References}

1. Taylor LH, Latham SM, Woolhouse ME. Risk factors for human disease emergence. Philos Trans R Soc Lond B Biol Sci. 2001;356(1411):983-9. https://doi.org/10.1098/rstb.2001.0888.
2. Horwitz P, Wilcox BA. Parasites, ecosystems and sustainability: an ecological and complex systems perspective. Int J Parasitol. 2005;35(7):72532. https://doi.org/10.1016/j.ijpara.2005.03.002.

3. Keesing F, Belden LK, Daszak P, Dobson A, Harvell CD, Holt RD, et al. Impacts of biodiversity on the emergence and transmission of infectious diseases. Nature. 2010;468(7324):647-52. https://doi.org/10.1038/ nature09575.

4. Wood CL, Lafferty KD, DeLeo G, Young HS, Hudson PJ, Kuris AM. Does biodiversity protect humans against infectious disease? Ecology. 95(4):817-32. https://doi.org/10.1890/13-1041.1

5. CBD-WHO, 2015: https://www.cbd.int/health/SOK-biodiversity-en.pdf. Accessed 17 July 2018.

6. PNSE3, 2014: http://solidarites-sante.gouv.fr/IMG/pdf/pnse3_v_finale. pdf. Accessed 17 July 2018.

7. Becker N, Petrić D, Boase C, Lane J, Zgomba M, Dahl C, Kaiser A. Mosquitoes and their control. New York Springer. 2003;2:441-81. https://doi. org/10.1007/978-3-540-92874-4.

8. World Bank. 2010. People, pathogens, and our planet : Volume one : towards a one health approach for controlling zoonotic diseases (English). Washington, DC: World Bank. http://documents.worldbank.org/ curated/en/214701468338937565/Volume-one-towards-a-one-healthapproach-for-controlling-zoonotic-diseases. Accessed 17 July 2018.

9. Anses. Mesures de maîtrise de la brucellose chez les bouquetins du Bargy. 2015. https://www.anses.fr/fr/system/files/SANT2014sa0218Ra. pdf. Accessed 17 July 2018.

10. Anses. Avis relatif au périmètre optimal de dépeuplement préventif influenza aviaire IA HP H5N8. 2017. https://www.anses.fr/fr/system/ files/SABA2017SA0011.pdf. Accessed 17 July 2018.

11. Brown AW. Insecticide resistance in mosquitoes: a pragmatic review. J Am Mosq Control Assoc. 1986;2(2):123-40.

12. Hemingway J, Ranson H. Insecticide Resistance in Insect Vectors of Human Disease. Ann Rev Entomol. 2000;45(1):371-91. https://doi.org/ 10.1146/annurev.ento.45.1.371.

13. Hemingway J, Ranson H, Magill A, Kolaczinski J, Fornadel C, Gimnig $J$, et al. Averting a malaria disaster: will insecticide resistance derail malaria control? The Lancet avr. 2016;387(10029):1785-8. https://doi. org/10.1016/S0140-6736(15)00417-1.

14. World Health Organization. World malaria report 2015. World Health Organization. http://apps.who.int/iris/bitstream/handle/10665/200018/ 9789241565158_eng.pdf;jsessionid=DF1B06C78C3F489DD7B69EF5A B105D15? sequence=1. Accessed 17 July 2018

15. Bennett R, Willis K. Public opinions on badger populations and the control of tuberculosis in cattle in the uk. Vet Rec. 2007;160(8):266-8. https://doi.org/10.1136/vr.160.8.266.

16. Schmidt KA, Ostfeld RS. Biodiversity and the dilution effect in disease ecology. Ecology. 82(3):609-19. https://doi.org/10.1890/00129658(2001)082[0609:BATDEI]2.0.CO;2

17. LoGiudice K, Ostfeld RS, Schmidt KA, Keesing F. The ecology of infectious disease: effects of host diversity and community composition on Lyme disease risk. Proc Natl Acad Sci. 100(2);567-571. https://doi.org/ 10.1073/pnas.0233733100.

18. Johnson PTJ, Thieltges DW. Diversity, decoys and the dilution effect: how ecological communities affect disease risk. J Exp Biol. 2010;213(6):961-70. https://doi.org/10.1242/jeb.037721.

19. Randolph SE, Dobson ADM. Pangloss revisited: a critique of the dilution effect and the biodiversity-buffers-disease paradigm. Parasitology. 2012;139(07):847-63. https://doi.org/10.1017/S0031182012000200.

20. Civitello DJ, Cohen J, Fatima H, Halstead NT, Liriano J, McMahon TA, et al. Biodiversity inhibits parasites: broad evidence for the dilution effect. Proc Natl Acad Sci. 2015;112(28):8667-71. https://doi.org/10. 1073/pnas.1506279112.

21. Ostfeld RS, Keesing F. The function of biodiversity in the ecology of vector-borne zoonotic diseases. Can J Zool. 2000;78:18.

22. Ostfeld RS, Keesing F. Effects of host diversity on infectious disease. Ann Rev Ecol Evol Syst. 2012;43(1):157-82. https://doi.org/10.1146/annurevecolsys-102710-145022.

23. Allan BF, Keesing F, Ostfeld RS. Effect of forest fragmentation on lyme disease risk. Conserv Biol. 2003;17(1):267-72. https://doi.org/10.1046/j. 1523-1739.2003.01260.x. 
24. Marm Kilpatrick A, Daszak P, Jones MJ, Marra PP, Kramer LD. Host heterogeneity dominates West Nile virus transmission. Proc Biol Sci. 2006;273(1599):2327-33. https://doi.org/10.1098/rspb.2006.3575.

25. Kilpatrick AM. Globalization, land use and the invasion of West Nile virus. Science. 2011;334(6054):323-7. https://doi.org/10.1126/science. 1201010.

26. Johnson PTJ, Preston DL, Hoverman JT, Richgels KLD. Biodiversity decreases disease through predictable changes in host community competence. Nature. 2013;494(7436):230-3. https://doi.org/10.1038/ nature11883.

27. Keesing F, Brunner J, Duerr S, Killilea M, LoGiudice K, Schmidt K, et al. Hosts as ecological traps for the vector of Lyme disease. Proc R Soc B Biol Sci 2009;276(1675):3911-9. https://doi.org/10.1098/rspb.2009.1159

28. Jaenson TGT, Tälleklint L. Incompetence of Roe Deer as Reservoirs of the Lyme Borreliosis Spirochete. J Med Entomol. 1992;29(5):813-7. https:// doi.org/10.1093/jmedent/29.5.813.

29. Kiffner C, Lödige C, Alings M, Vor T, Rühe F. Attachment site selection of ticks on roe deer. Capreolus capreolus Exp Appl Acarol. 2011;53(1):7994. https://doi.org/10.1007/s10493-010-9378-4.

30. Johnson PT, Lund PJ, Hartson RB, Yoshino TP. Community diversity reduces Schistosoma mansoni transmission, host pathology and human infection risk. Proc R Soc B Biol Sci. 2009;276(1662):1657-63. https://doi.org/10.1098/rspb.2008.1718.

31. Reiskind MH, Wund MA. Experimental assessment of the impacts of Northern Long-Eared Bats on Ovipositing Culex (Diptera: Culicidae) Mosquitoes. J Med Entomol. 2009;46(5):1037-44. https://doi.org/10. 1603/033.046.0510.

32. Levi T, Kilpatrick AM, Mangel M, Wilmers CC. Deer, predators, and the emergence of Lyme disease. PNAS. https://doi.org/10.1073/pnas.12045 36109

33. Sokolow $\mathrm{SH}$, Huttinger $\mathrm{E}$, Jouanard $\mathrm{N}$, Hsieh MH, Lafferty KD, Kuris AM, et al. Reduced transmission of human schistosomiasis after restoration of a native river prawn that preys on the snail intermediate host. Proc Natl Acad Sci. 2015;112(31):9650-5. https://doi.org/10.1073/pnas.15026 51112.

34. Ostfeld RS, Holt RD. Are predators good for your health? Evaluating evidence for top-down regulation of zoonotic disease reservoirs. Front Ecol Environ. 2004;2(1):13-20. https://doi.org/10.1890/1540-9295(2004) 002[0013:APGFYH]2.0.CO;2.

35. Giraudoux P, Craig PS, Delattre P, Bao G, Bartholomot B, Harraga S, et al. Interactions between landscape changes and host communities can regulate Echinococcus multilocularis transmission. Parasitology. 2003;127(7):S119-29. https://doi.org/10.1017/S0031182003003512.

36. Weber JM, Aubry S. Predation by foxes, Vulpes vulpes, on the fossorial form of the water vole, Arvicola terrestris scherman, in western Switzerland. J Zool. 1993;229(4):553-9. https://doi.org/10.1111/j.1469-7998. 1993.tb02656.x.

37. Lugassy L, Amdouni-Boursier L, Alout H, Berrebi R, Boëte C, Boué F, et al. What is the evidence that ecosystem components or functions have an impact on infectious diseases? A systematic review protocol. Environm Evid. 2019;8(1):4. https://doi.org/10.1186/s13750-019-0147-5.

38. Collaboration for Environmental Evidence. Guidelines and Standards for Evidence synthesis in Environmental Management. Version 5.0 (AS Pullin, GK Frampton, B Livoreil \& G Petrokofsky, Eds, 2018. www.envir onmentalevidence.org/information-for-authors. Accessed 13 Jan 2020.

39. IUCN. 2012. http://s3.amazonaws.com/iucnredlist-newcms/staging/ public/attachments/3125/dec_2012_guidance_habitats_classification_ scheme.pdf. Accessed 17 July 2018.

40. Ferrell AM, Brinkerhoff RJ. Using landscape analysis to test hypotheses about drivers of tick abundance and infection prevalence with Borrelia burgdorferi. Int J Environ Res Public Health. 2018;15(4):737. https://doi. org/10.3390/ijerph15040737.

41. de Mik EL, van Pelt W, Docters-van Leeuwen BD, van der Veen A, Schellekens JF, Borgdorff MW. The geographical distribution of tick bites and erythema migrans in general practice in The Netherlands. Int J Epidemiol. 1997;26(2):451-7. https://doi.org/10.1093/ije/26.2.451.

42. Ostfeld RS, Levi T, Keesing F, Oggenfuss K, Canham CD. Tick-borne disease risk in a forest food web. Ecology. 2018;99(7):1562-73. https:// doi.org/10.1002/ecy.2386.

43. Williams SC, Ward JS, Worthley TE, Stafford KC III. Managing Japanese barberry (Ranunculales: Berberidaceae) infestations reduces blacklegged tick (Acari: Ixodidae) abundance and infection prevalence with Borrelia burgdorferi (Spirochaetales: Spirochaetaceae). Environ Entomol. 2009:38(4):977-84.

44. Williams SC, Ward JS. Effects of Japanese barberry (Ranunculales: Berberidaceae) removal and resulting microclimatic changes on Ixodes scapularis (Acari: Ixodidae) abundances in Connecticut, USA. Environ Entomol. 2010;39(6):1911-21. https://doi.org/10.1603/EN10131.

45. Williams SC, Linske MA, Ward JS. Long-term effects of Berberis thunbergii (Ranunculales: Berberidaceae) management on Ixodes scapularis (Acari: Ixodidae) abundance and Borrelia burgdorferi (Spirochaetales: Spirochaetaceae) prevalence in Connecticut, USA. Environ Entomol. 2017;46(6):1329-38. https://doi.org/10.1093/ee/nvx146.

46. Mysterud A, Easterday WR, Stigum VM, Aas AB, Meisingset EL, Viljugrein $\mathrm{H}$. Contrasting emergence of Lyme disease across ecosystems. Nat Commun. 2016;7:11882. https://doi.org/10.1038/ncomms11882.

47. Hubálek Z, Halouzka J, Juřicová Z, Šikutová S, Rudolf I. Effect of forest clearing on the abundance of Ixodes ricinus ticks and the prevalence of Borrelia burgdorferi sl. Med Vet Entomol. 2006;20(2):166-72. https://doi. org/10.1111/j.1365-2915.2006.00615.x.

48. Gray JS, Kahl O, Janetzki C, Stein J. Studies on the ecology of Lyme disease in a deer forest in County Galway. Ireland J Med Entomol. 1992;29(6):915-20. https://doi.org/10.1093/jmedent/29.6.915.

49. Halstead NT, Hoover CM, Arakala A, Civitello DJ, De Leo GA, Gambhir et al. Agrochemicals increase risk of human schistosomiasis by supporting higher densities of intermediate hosts. Nat Commun. 2018; 9(1), 837. https://doi.org/10.1038/s41467-018-03189-w

50. Yupiana Y, de Vlas SJ, Adnan NM, Richardus JH. Risk factors of poultry outbreaks and human cases of H5N1 avian influenza virus infection in West Java Province. Indonesia Int J Infect Dis. 2010;14(9):e800-5. https://doi.org/10.1016/j.ijid.2010.03.014.

51. Fuller TL, Gilbert M, Martin V, Cappelle J, Hosseini P, Njabo KY, et al. Predicting hotspots for influenza virus reassortment. Emerg Infect Dis. 2013;19(4):581. https://doi.org/10.3201/eid1904.120903.

52. Saksena S, Fox J, Epprecht M, Tran CC, Nong DH. Spencer JH, et al. Evidence for the convergence model: the emergence of highly pathogenic avian influenza (H5N1) in Viet Nam. PLoS One. 2015;10(9):e0138138. https://doi.org/10.1371/journal.pone.0138138

53. Paul MC, Gilbert M, Desvaux S, Andriamanivo HR, Peyre M, Khong NV, et al. Agro-environmental determinants of avian influenza circulation: a multisite study in Thailand, Vietnam and Madagascar. PLoS ONE. 2014;9(7):e101958. https://doi.org/10.1371/journal.pone.0101958.

54. Pfeiffer DU, Minh PQ, Martin V, Epprecht M, Otte MJ. An analysis of the spatial and temporal patterns of highly pathogenic avian influenza occurrence in Vietnam using national surveillance data. Vet J. 2007;174(2):302-9. https://doi.org/10.1016/j.tvjl.2007.05.010.

55. Takekawa J, Prosser D, Collins B, Douglas D, Perry W, Yan B, et al. Movements of wild ruddy shelducks in the Central Asian Flyway and their spatial relationship to outbreaks of highly pathogenic avian influenza H5N1. Viruses. 2013;5(9):2129-52. https://doi.org/10.3390/v5092129.

56. Thanapongtharm W, Van Boeckel TP, Biradar C, Xiao X, Gilbert M. Rivers and flooded areas identified by medium-resolution remote sensing improve risk prediction of the highly pathogenic avian influenza H5N1 in Thailand. Geospat Health. 2013;8(1):193. https://doi.org/10.4081/gh. 2013.66.

57. Nallar R, Papp Z, Leighton FA, Epp T, Pasick J, Berhane Y, et al. Ecological determinants of avian influenza virus, West Nile virus, and avian paramyxovirus infection and antibody status in blue-winged teal (Anas Discors) in the Canadian prairies. J Wildl Dis. 2016;52(1):33-46. https:// doi.org/10.7589/2013-07-191.

58. Huang S, Tian H, Wu X, Zhou S, Li X, Zhang T, et al. Risk analysis of H5N1 highly pathogenic avian influenza in poultry at the Poyang Lake area, China. Environ Earth Sci. 2016;75(11):955. https://doi.org/10.1007/ s12665-015-5111-2.

59. Si Y, de Boer WF, Gong P. Different environmental drivers of highly pathogenic avian influenza H5N1 outbreaks in poultry and wild birds. PLOS ONE. 2013;8(1):e53362. https://doi.org/10.1371/journal.pone. 0053362.

60. Newman SH, Iverson SA, Takekawa JY, Gilbert M, Prosser DJ, Batbayar N, et al. Migration of whooper swans and outbreaks of highly pathogenic avian influenza H5N1 virus in eastern Asia. PLoS ONE. 2009;4(5):e5729. https://doi.org/10.1371/journal.pone.0005729. 
61. Gaidet N, Caron A, Cappelle J, Cumming GS, Balança G, Hammoumi $S$, et al. Understanding the ecological drivers of avian influenza virus infection in wildfowl: a continental-scale study across Africa. Proc R Soc B Biol Sci. 2011;279(1731):1131-41. https://doi.org/10.1098/rspb.2011. 1417.

62. Bekara MEA, Azizi L, Bénet JJ, Durand B. Spatial-temporal Variations of Bovine Tuberculosis Incidence in F rance between 1965 and 2000. Transbound Emerg Dis. 2016;63(1):101-13. https://doi.org/10.1111/ tbed.12224.

63. Bouchez-Zacria M, Courcoul A, Jabert P, Richomme C, Durand B. Environmental determinants of the Mycobacterium bovis concomitant infection in cattle and badgers in France. Eur J Wildl Res. 2017;63(5):74. https://doi.org/10.1007/s10344-017-1131-4.

64. Porphyre T, Stevenson MA, McKenzie J. Risk factors for bovine tuberculosis in New Zealand cattle farms and their relationship with possum control strategies. Prev Vet Med. 2008;86(1-2):93-106. https://doi.org/ 10.1016/j.prevetmed.2008.03.008.

65. Walter WD, Smith R, Vanderklok M, VerCauteren KC. Linking bovine tuberculosis on cattle farms to white-tailed deer and environmental variables using Bayesian hierarchical analysis. PLOS ONE. 2014;9(3):e90925. https://doi.org/10.1371/journal.pone.0090925.

66. Huang ZYX, Xu C, Van Langevelde F, Prins HHT, Jebara KB, De Boer WF. Dilution effect and identity effect by wildlife in the persistence and recurrence of bovine tuberculosis. Parasitology. 2014;141(7):981-7. https://doi.org/10.1017/S0031182013002357.

67. Sintayehu DW, Heitkoënig IM, Prins HH, Tessema ZK, De Boer WF. Effect of host diversity and species assemblage composition on bovine tuberculosis (bTB) risk in Ethiopian cattle. Parasitology. 2017;144(6):783-92. https://doi.org/10.1017/S0031182013002357.

68. Santos N, Correia-Neves M, Ghebremichael S, Källenius G, Svenson SB, Almeida V. Epidemiology of Mycobacterium bovis infection in wild boar (Sus scrofa) from Portugal. JWildl Dis. 2009;45(4):1048-61. https://doi. org/10.7589/0090-3558-45.4.1048.

69. Caron A, Miguel E, Gomo C, Makaya P, Pfukenyi DM, Foggin C, et al. Relationship between burden of infection in ungulate populations and wild life/livestock interfaces. Epidemiol Infect. 2013;141(7):1522-35. https://doi.org/10.1017/S0950268813000204.

70. Pikula J, Beklova M, Holesovska Z, Skocovska B, Treml F. Ecology of brucellosis of the European hare in the Czech Republic. Veterinarni Medicina. 2005; 50(3), 105-109. https://doi.org/10.17221/5602-VETMED

71. Muñoz PM, Boadella M, Arnal M, de Miguel MJ, Revilla M, Martínez D, et al. Spatial distribution and risk factors of Brucellosis in Iberian wild ungulates. BMC Infect Dis. 2010;10(1):46. https://doi.org/10.1186/ 1471-2334-10-46.

72. Jia P, Joyner A. Human brucellosis occurrences in inner mongolia, China: a spatio-temporal distribution and ecological niche modeling approach. BMC Infect Dis. 2015;15(1):36. https://doi.org/10.1186/ s12879-015-0763-9.

73. Brennan A, Cross PC, Portacci K, Scurlock BM, Edwards WH. Shifting brucellosis risk in livestock coincides with spreading seroprevalence in elk. PLoS ONE. 2017;12(6):e0178780. https://doi.org/10.1371/journal. pone. 0178780.

74. Nina PM, Leirs H, Mugisha S, Van Damme P. Relative importance of wildlife and livestock transmission route of brucellosis in southwestern Uganda. Data in brief. 2018;19:1080-5. https://doi.org/10.1016/j.dib. 2018.05.135.

75. Ferrari MJ, Garrott RA. Bison and elk: brucellosis seroprevalence on a shared winter range. J Wild life Manage. 2002; 1246-1254. https://doi. org/10.2307/3802957

76. Sheela AM, Ghermandi A, Vineetha P, Sheeja RV, Justus J, Ajayakrishna $\mathrm{K}$. Assessment of relation of land use characteristics with vector-borne diseases in tropical areas. Land Use Policy. 2017;63:369-80. https://doi. org/10.1016/j.landusepol.2017.01.047.

77. Diallo D, Sall AA, Buenemann M, Chen R, Faye O, Diagne CT, et al. Landscape ecology of sylvatic chikungunya virus and mosquito vectors in southeastern Senegal. PLoS Negl Trop Dis. 2012;6(6):e1649. https://doi. org/10.1371/journal.pntd.0001649.

78. Jagai JS, Griffiths JK, Kirshen PH, Webb P, Naumova EN. Patterns of protozoan infections: spatiotemporal associations with cattle density. EcoHealth. 2010;7(1):33-46. https://doi.org/10.1007/s10393-010-0286-1.
79. Kilonzo C, Li X, Vivas EJ, Jay-Russell MT, Fernandez KL, Atwill ER. Fecal shedding of zoonotic food-borne pathogens by wild rodents in a major agricultural region of the central California coast. Appl Environ Microbiol. 2013;79(20):6337-44. https://doi.org/10.1128/AEM.01503-13.

80. Bajer A. Between-year variation and spatial dynamics of Cryptosporidium spp. and Giardia spp. infections in naturally infected rodent populations. Parasitology. 2008;135(14):1629-49. https://doi.org/10. 1017/S0031182008004952.

81. Atwill ER, Sweitzer RA, Pereira MG, Gardner IA, Van Vuren D, Boyce WM. Prevalence of and associated risk factors for shedding Cryptosporidium parvum oocysts and Giardia cysts within feral pig populations in California. Appl Environ Microbiol. 1997;63(10):3946-9.

82. Bett B, Said MY, Sang R, Bukachi S, Wanyoike S, Kifugo SC, et al. Effects of flood irrigation on the risk of selected zoonotic pathogens in an arid and semi-arid area in the eastern Kenya. PLOS ONE. 2017;12(5):e0172626. https://doi.org/10.1371/journal.pone.0172626.

83. Tiong V, Abd-Jamil J, Zan MH, Abu-Bakar RS, Ew CL, Jafar FL, et al. Evaluation of land cover and prevalence of dengue in Malaysia. Trop Biomed. 2015;32(4):587-97.

84. Araujo RV, Albertini MR, Costa-da-Silva AL, Suesdek L, Franceschi NCS, Bastos NM. São Paulo urban heat islands have a higher incidence of dengue than other urban areas. Braz J Infect Dis. 2015;19(2):146-55. https://doi.org/10.1016/j.bjid.2014.10.004.

85. Acharya BK, Cao C, Lakes T, Chen W, Naeem S, Pandit S. Modeling the spatially varying risk factors of dengue fever in Jhapa district, Nepal, using the semi-parametric geographically weighted regression model. Int J Biometeorol. 2018;62(11):1973-86. https://doi.org/10.1007/ s00484-018-1601-8.

86. Craig PS, Giraudoux P, Shi D, Bartholomot B, Barnish G, Delattre P, et al. An epidemiological and ecological study of human alveolar echinococcosis transmission in south Gansu. China Acta tropica. 2000;77(2):167-77.

87. Danson FM, Craig PS, Man W, Shi D, Giraudoux P. Landscape dynamics and risk modeling of human alveolar echinococcosis. Photogrammetr Eng Remote Sens. 2004;70(3):359-66.

88. Huang D, Li R, Qiu J, Sun X, Yuan R, Shi Y, et al. Geographical environment factors and risk mapping of human cystic echinococcosis in western China. Int J Environ Res Public Health. 2018;15(8):1729.

89. Piarroux M, Gaudart J, Bresson-Hadni S, Bardonnet K, Faucher B, Grenouillet $F$ et al. Landscape and climatic characteristics associated with human alveolar echinococcosis in France, 1982 to 2007, the FrancEchino network; 2015.

90. GiraudouX P, Raoul F, Pleydell D, Li T, Han X, Qiu J, et al. Drivers of Echinococcus multilocularis transmission in China: small mammal diversity, landscape or climate? PLoS Negl Trop Dis. 2013;7(3):e2045. https://doi. org/10.1371/journal.pntd.0002045.

91. Pleydell DR, Yang YR, Danson FM, Raoul F, Craig PS, McManus DP, et al. Landscape composition and spatial prediction of alveolar echinococcosis in southern Ningxia, China. PLoS Negl Trop Dis. 2008;2(9):e287. https://doi.org/10.1371/journal.pntd.0000287.

92. Viel JF, Giraudoux P, Abrial V, Bresson-Hadni S. Water vole (Arvicola terrestris scherman) density as risk factor for human alveolar echinococcosis. Am J Trop Med Hyg. 1999;61 (4):559-65. https://doi.org/10.4269/ ajtmh.1999.61.559.

93. Qian W, Xiao YF, Vuitton DA, Schantz PM, Raoul F, Budke C, et al. Impact of overgrazing on the transmission of Echinococcus multilocularisin Tibetan pastoral communities of Sichuan Province, China. Chin Med J. 2007;120(3):237-42.

94. Bastien M, Vaniscotte A, Combes B, Umhang G, Germain E, Gouley V et al. High density of fox and cat faeces in kitchen gardens and resulting rodent exposure to Echinococcus multilocularis and Toxoplasma gondii. Folia Parasitological. 2018; 65, 1-9. https://doi.org/10.14411/fp. 2018.002

95. Hegglin D, Bontadina F, Contesse P, Gloor S, Deplazes P. Plasticity of predation behaviour as a putative driving force for parasite life-cycle dynamics: the case of urban foxes and Echinococcus multilocularis tapeworm. Funct Ecol. 2007;21(3):552-60. https://doi.org/10.1111/j. 1365-2435.2007.01257.x.

96. Robardet E, Giraudoux P, Caillot C, Augot D, Boué F, Barrat J. Fox defecation behaviour in relation to spatial distribution of voles in an urbanised area: An increasing risk of transmission of Echinococcus multilocularis? 
Int J Parasitol. 2011;41(2):145-54. https://doi.org/10.1016/j.jpara.2010. 08.007 .

97. Qian W, Francis R, Christine B, Craig PS, Xiao YF, Vuitton DA, et al. Grass height and transmission ecology of Echinococcus multilocularisin Tibetan communities, China. Chin Med J. 2010;123(1):61-7. https://doi. org/10.3760/cma.j.issn.0366-6999.2010.01.011.

98. Saitoh T, Takahashi K. The role of vole populations in prevalence of the parasite (Echinococcus multilocularis) in foxes. Popul Ecol. 1998;40(1):97105. https://doi.org/10.1007/BF02765225.

99. Guberti V, Bolognini M, Lanfranchi P, Battelli G. Echinococcus granulosus in the wolf in Italy. Parassitologia. 2004;46(4):425.

100. Messier F, Rau ME, McNeill MA. Echinococcus granulosus (Cestoda: Taeniidae) infections and moose-wolf population dynamics in southwestern Quebec. Can J Zool. 1989:67(1):216-9.

101. Joly DO, Messier F. The distribution of Echinococcus granulosus in moose: evidence for parasite-induced vulnerability to predation by wolves? Oecologia. 2004;140(4):586-90. https://doi.org/10.1007/ s00442-004-1633-0.

102. Ocampo CB, Ferro MC, Cadena H, Gongora R, Pérez M, ValderramaArdila $\mathrm{CH}$, et al. Environmental factors associated with American cutaneous leishmaniasis in a new Andean focus in Colombia. Tropical Med Int Health. 2012;17(10):1309-17. https://doi.org/10.1111/j.1365-3156. 2012.03065.x.

103. Valderrama-Ardila C, Alexander N, Ferro C, Cadena H, Marín D, Holford $T R$, et al. Environmental risk factors for the incidence of American cutaneous leishmaniasis in a sub-Andean zone of Colombia (Chaparral, Tolima). Am J Trop Med Hyg. 2010;82(2):243-50. https://doi.org/10. 4269/ajtmh.2010.09-0218.

104. Nackers F, Mueller YK, Salih N, Elhag MS, Elbadawi ME, Hammam O, et al. Determinants of visceral leishmaniasis: a case-control study in Gedaref State, Sudan. PLoS NegI Trop Dis. 2015;9(11):e0004187. https://doi.org/ 10.1371/journal.pntd.0004187.

105. Feliciangeli MD, Delgado O, Suarez B, Bravo A. Leishmania and sand flies: proximity to woodland as a risk factor for infection in a rural focus of visceral leishmaniasis in west central Venezuela. Tropical Med Int Health. 2006;11(12):1785-91. https://doi.org/10.1111/j.1365-3156.2006. 01747.x.

106. Chaves LF, Cohen JM, Pascual M, Wilson ML. Social exclusion modifies climate and deforestation impacts on a vector-borne disease. PLoS Negl Trop Dis. 2008;2(2):e176. https://doi.org/10.1371/journal.pntd. 0000176.

107. Travi BL, Osorio Y, Becerra MT, Adler GH. Dynamics of Leishmania chagasi infection in small mammals of the undisturbed and degraded tropical dry forests of northern Colombia. Trans R Soc Trop Med Hyg. 1998;92(3):275-8. https://doi.org/10.1016/S0035-9203(98)91009-4.

108. Soares VB, Almeida ASD, Sabroza PC, Vargas WP. Epidemiological surveillance of tegumentary leishmaniasis: local territorial analysis. Rev Saude Publica. 2017;51:51. https://doi.org/10.1590/S1518-8787.2017051006 614.

109. Wasserberg G, Abramsky Z, Anders G, El-Fari M, Schoenian G, Schnur L, et al. The ecology of cutaneous leishmaniasis in Nizzana, Israel: infection patterns in the reservoir host, and epidemiological implications. Int J Parasitol. 2002;32(2):133-43. https://doi.org/10.1890/1051-0761(2003) 013[0868:ADEOOC]2.0.CO;2.

110. Cerbino Neto J, Werneck GL, Costa CHN. Factors associated with the incidence of urban visceral leishmaniasis: an ecological study in Teresina, Piauí State. Brazil Cadernos de Saúde Pública. 2009;25(7):1543-51. https://doi.org/10.1590/S0102-311X2009000700012.

111. Saraiva L, Andrade Filho JD, Falcão AL, de Carvalho DAA, de Souza CM, Freitas CR, et al. Phlebotominae fauna (Diptera: Psychodidae) in an urban district of Belo Horizonte, Brazil, endemic for visceral leishmaniasis: characterization of favored locations as determined by spatial analysis. Acta Trop. 2011;117(2):137-45. https://doi.org/10.1016/j.actat ropica.2010.11.007.

112. Yuval B. Populations of Phlebotomus papatasi (Diptera: Psychodidae) and the risk of Leishmania major transmission in three Jordan Valley habitats. J Med Entomol. 1991;28(4):492-5. https://doi.org/10.1093/ jmedent/28.4.492.

113. Bhunia GS, Kumar V, Kumar AJ, Das P, Kesari S. The use of remote sensing in the identification of the eco-environmental factors associated with the risk of human visceral leishmaniasis (kala-azar) on the Gangetic plain, in north-eastern India. Ann Trop Med Parasitol. 2010;104(1):3553. https://doi.org/10.1179/136485910X12607012373678.

114. Ghatee MA, Haghdoost AA, Kooreshnia F, Kanannejad Z, Parisaie Z, Karamian M, Moshfe A. Role of environmental, climatic risk factors and livestock animals on the occurrence of cutaneous leishmaniasis in newly emerging focus in Iran. J Infect Public Health. 2018;1 1(3):425-33. https://doi.org/10.1016/j.jiph.2017.12.004.

115. Bellali H, Talmoudi K, Alaya NB, Mahfoudhi M, Ennigrou S, Chahed MK. Effect of temperature, rainfall and relative density of rodent reservoir hosts on zoonotic cutaneous leishmaniasis incidence in Central Tunisia. Asian Pac J Trop Dis. 2017;7(2):88-96.

116. Derne BT, Fearnley EJ, Lau CL, Paynter S, Weinstein P. Biodiversity and leptospirosis risk: a case of pathogen regulation? Med Hypotheses. 2011;77(3):339-44. https://doi.org/10.1016/j.mehy.2011.05.009.

117. Tulsiani SM, Cobbold RN, Graham GC, Dohnt MF, Burns MA, Leung LP, et al. The role of fruit bats in the transmission of pathogenic leptospires in Australia. Ann Trop Med Parasitol. 2011;105(1):71-84. https://doi.org/ 10.1179/136485911X12899838413501.

118. Theuerkauf J, Perez J, Taugamoa A, Niutoua I, Labrousse D, Gula R, et al. Leptospirosis risk increases with changes in species composition of rat populations. Naturwissenschaften. 2011;100(4):385-8. https://doi.org/ 10.1007/s00114-013-1033-6.

119. Lovera R, Fernández MS, Jacob J, Lucero N, Morici G, Brihuega B, et al. Intrinsic and extrinsic factors related to pathogen infection in wild small mammals in intensive milk cattle and swine production systems. PLoS Negl Trop Dis. 2017;11(6):e0005722. https://doi.org/10.1371/journal. pntd.0005722.

120. Millán J, Cevidanes A, Chirife AD, Candela MG, León-Vizcaíno L. Risk factors of Leptospira infection in Mediterranean periurban micromammals. Zoonoses Public Health. 2018;65(1):e79-85. https://doi.org/10. 1111/zph.12411.

121. Halos L, Bord S, Cotté V, Gasqui P, Abrial D, Barnouin J, et al. Ecological factors characterizing the prevalence of bacterial tick-borne pathogens in Ixodes ricinus ticks in pastures and woodlands. Appl Environ Microbiol. 2010;76(13):4413-20. https://doi.org/10.1128/AEM.00610-10.

122. Ehrmann S, Ruyts SC, Scherer-Lorenzen M, Bauhus J, Brunet J, Cousins SA, et al. Habitat properties are key drivers of Borrelia burgdorferi (sl.) prevalence in Ixodes ricinus populations of deciduous forest fragments. Parasites Vectors. 2018;11(1):23. https://doi.org/10.1186/ s13071-017-2590-x.

123. Brownstein JS, Skelly DK, Holford TR, Fish D. Forest fragmentation predicts local scale heterogeneity of Lyme disease risk. Oecologia. 2005;146(3):469-75. https://doi.org/10.1007/s00442-005-0251-9.

124. Seukep SE, Kolivras KN, Hong Y, Li J, Prisley SP, Campbell JB, et al. An examination of the demographic and environmental variables correlated with Lyme disease emergence in Virginia. EcoHealth. 2015;12(4):634-44. https://doi.org/10.1007/s10393-015-1034-3.

125. Ruyts SC, Landuyt D, Ampoorter E, Heylen D, Ehrmann S, Coipan EC, et al. Low probability of a dilution effect for Lyme borreliosis in Belgian forests. Ticks Tick-borne Dis. 2018;9(5):1143-52. https://doi.org/10. 1016/j.ttbdis.2018.04.016

126. Ruyts SC, Tack W, Ampoorter E, Coipan EC, Matthysen E, Heylen D, et al. Year-to-year variation in the density of Ixodes ricinus ticks and the prevalence of the rodent-associated human pathogens Borrelia afzelii and B. miyamotoi in different forest types. Ticks Tick-borne Dis. 2018;9(2):141-5. https://doi.org/10.1016/j.ttbdis.2017.08.008.

127. Gassner F, van Vliet AJ, Burgers SL, Jacobs F, Verbaarschot P, Hovius EK, et al. Geographic and temporal variations in population dynamics of Ixodes ricinus and associated Borrelia infections in The Netherlands. Vector-Borne Zoonotic Dis. 2011;11(5):523-32. https://doi.org/10.1089/ vbz.2010.0026.

128. Lynn GE, Graham CB, Horiuchi K, Eisen L, Johnson TL, Lane RS, Eisen RJ. Prevalence and geographic distribution of Borrelia miyamotoi in host-seeking Ixodes pacificus (Acari: Ixodidae) nymphs in Mendocino County. California J Med Entomol. 2018;55(3):711-6. https://doi.org/10. 1093/jme/tjx258.

129. Eisen RJ, Eisen L, Girard YA, Fedorova N, Mun J, Slikas B, et al. A spatiallyexplicit model of acarological risk of exposure to Borrelia burgdorferiinfected Ixodes pacificus nymphs in northwestern California based on woodland type, temperature, and water vapor. Ticks Tick-borne Dis. 2010;1(1):35-43. https://doi.org/10.1016/j.ttbdis.2009.12.002. 
130. Swei A, Ostfeld RS, Lane RS, Briggs CJ. Impact of the experimental removal of lizards on Lyme disease risk. Proc R Soc B Biol Sci. 2011;278(1720):2970-8. https://doi.org/10.1098/rspb.2010.2402.

131. Werden L, Barker IK, Bowman J, Gonzales EK, Leighton PA, Lindsay LR, et al. Geography, deer, and host biodiversity shape the pattern of Lyme disease emergence in the Thousand Islands Archipelago of Ontario, Canada. PLoS ONE. 2014;9(1):e85640. https://doi.org/10.1371/journal. pone.0085640.

132. James MC, Bowman AS, Forbes KJ, Lewis F, McLeod JE, Gilbert L. Environmental determinants of Ixodes ricinus ticks and the incidence of Borrelia burgdorferi sensu lato, the agent of Lyme borreliosis. Scotland Parasitology. 2013;140(2):237-46. https://doi.org/10.1017/S003118201 200145X.

133. Vourc'h G, Abrial D, Bord S, Jacquot M, Masséglia S, Poux V, et al. Mapping human risk of infection with Borrelia burgdorferi sensu lato, the agent of Lyme borreliosis, in a periurban forest in France. Ticks Tickborne Dis. 2016;7(5):644-52. https://doi.org/10.1016/j.ttbdis.2016.02 008.

134. Zeman P, Daniel M. Mosaic pattern of Borrelia infection in a continuous population of the tick Ixodes ricinus (Acari: Ixodidae). Exp Appl Acarol. 1999;23(4):327-35. https://doi.org/10.1023/A:1006167001554.

135. Delgado JD, Abreu-Yanes E, Abreu-Acosta N, Flor MD, Foronda P. Vertebrate ticks distribution and their role as vectors in relation to road edges and underpasses. Vector-Borne Zoonotic Dis. 2017;17(6):376-83. https://doi.org/10.1089/vbz.2016.2073.

136. Prusinski MA, Chen H, Drobnack JM, Kogut SJ, Means RG, Howard JJ, et al. Habitat structure associated with Borrelia burgdorferi prevalence in small mammals in New York State. Environ Entomol. 2006;35(2):30819. https://doi.org/10.1603/0046-225X-35.2.308.

137. Guerra MA, Walker ED, Kitron U. Canine surveillance system for Lyme borreliosis in Wisconsin and northern Illinois: geographic distribution and risk factor analysis. Am J Trop Med Hyg. 2001;65(5):546-52. https:// doi.org/10.4269/ajtmh.2001.65.546.

138. Bouchard C, Beauchamp G, Leighton PA, Lindsay R, Bélanger D, Ogden $\mathrm{NH}$. Does high biodiversity reduce the risk of Lyme disease invasion? Parasites Vectors. 2013;6(1):195. https://doi.org/10.1186/ 1756-3305-6-195.

139. Rizzoli A, Merler S, Furlanello C, Genchi C. Geographical information systems and bootstrap aggregation (bagging) of tree-based classifiers for Lyme disease risk prediction in Trentino, Italian Alps. J Med Entomol. 2002;39(3):485-92. https://doi.org/10.1603/0022-2585-39.3.485.

140. States SL, Brinkerhoff RJ, Carpi G, Steeves TK, Folsom-O'Keefe C, DeVeaux M, Diuk-Wasser MA. Lyme disease risk not amplified in a species-poor vertebrate community: similar Borrelia burgdorferi tick infection prevalence and OspC genotype frequencies. Infect Genet Evol 2014; 27, 566-575. https://doi.org/10.1016/j.meegid.2014.04.014

141. Ruiz-Fons F, Fernández-de-Mera IG, Acevedo P, Gortázar C, de la Fuente J. Factors driving the abundance of Ixodes ricinus ticks and the prevalence of zoonotic I. ricinus-borne pathogens in natural foci. Appl Environ Microbiol. 2012; 78(8), 2669-2676. https://doi.org/10.1128/ AEM.06564-11

142. Raizman EA, Holland JD, Keefe LM, Moro MH. Forest and surface water as predictors of Borrelia burgdorferi and its vector Ixodes scapularis (Acari: Ixodidae) in Indiana. J Med Entomol. 2010;47(3):458-65. https:// doi.org/10.1093/jmedent/47.3.458.

143. Tack W, Madder M, Baeten L, De Frenne P, Verheyen K. The abundance of Ixodes ricinus ticks depends on tree species composition and shrub cover. Parasitology. 2012;139(10):1273-81. https://doi.org/10.1017/ S0031182012000625.

144. Michalik J, Hofman T, Buczek A, Skoracki M, Sikora B. Borrelia burgdorferi sl in Ixodes ricinus (Acari: Ixodidae) ticks collected from vegetation and small rodents in recreational areas of the city of Poznań. J Med Entomol. 2003;40(5):690-7. https://doi.org/10.1603/0022-2585-40.5.690.

145. Ruyts SC, Ampoorter EVY, Coipan EC, Baeten L, Heylen D, Sprong $\mathrm{H}$, et al. Diversifying forest communities may change Lyme disease risk: extra dimension to the dilution effect in Europe. Parasitology. 2016;143(10):1310-9. https://doi.org/10.1017/S0031182016000688.

146. Jensen PM, Hansen H, Frandsen F. Spatial risk assessment for Lyme borreliosis in Denmark. Scand J Infect Dis. 2000;32(5):545-50. https://doi. org/10.1080/003655400458857.
147. Millins C, Gilbert L, Johnson P, James M, Kilbride E, Birtles R, Biek R. Heterogeneity in the abundance and distribution of Ixodes ricinus and Borrelia burgdorferi (sensu lato) in Scotland: implications for risk prediction. Parasites Vectors. 2016;9(1):595. https://doi.org/10.1186/ s13071-016-1875-9.

148. Ostfeld RS, Schauber EM, Canham CD, Keesing F, Jones CG, Wolff JO. Effects of acorn production and mouse abundance on abundance and Borrelia burgdorferi infection prevalence of nymphal Ixodes scapularis ticks. Vector Borne Zoonotic Dis. 2001;1(1):55-63.

149. Perez G, Bastian S, Chastagner A, Agoulon A, Plantard O, Vourc'h G, Butet A. Ecological factors influencing small mammal infection by Anaplasma phagocytophilum and Borrelia burgdorferi sl in agricultural and forest landscapes. Environ Microbiol. 2017;19(10):4205-19. https:// doi.org/10.1111/1462-2920.13885.

150. Linske MA, Williams SC, Stafford KC III, Ortega IM. Ixodes scapularis (Acari: Ixodidae) Reservoir Host Diversity and Abundance Impacts on Dilution of Borrelia burgdorferi (Spirochaetales: Spirochaetaceae) in Residential and Woodland Habitats in Connecticut. US J Med Entomol. 2018;55(3):681-90. https://doi.org/10.1093/jme/tj×237.

151. Ostfeld RS, Canham CD, Oggenfuss K, Winchcombe RJ, Keesing F. Climate, deer, rodents, and acorns as determinants of variation in Lymedisease risk. PLoS Biol. 2006;4(6):e145. https://doi.org/10.1371/journal. pbio.0040145.

152. Hofmeester TR, Jansen PA, Wijnen HJ, Coipan EC, Fonville M, Prins HH. Cascading effects of predator activity on tick-borne disease risk. Proc $\mathrm{R}$ Soc B Biol Sci. 1859;2017(284):20170453. https://doi.org/10.1098/rspb. 2017.0453.

153. Lainhart W, Bickersmith SA, Nadler KJ, Moreno M, Saavedra MP, Chu VM, et al. Evidence for temporal population replacement and the signature of ecological adaptation in a major Neotropical malaria vector in Amazonian Peru. Malar J. 2015;14(1):375. https://doi.org/10.1186/ s12936-015-0863-4.

154. Fornace KM, Abidin TR, Alexander N, Brock P, Grigg MJ, Murphy A, et al. Association between landscape factors and spatial patterns of Plasmodium knowlesi infections in Sabah, Malaysia. Emerg Infect Dis. 2016;22(2):201. https://doi.org/10.3201/eid2202.150656.

155. Stefani A, Roux E, Fotsing JM, Carme B. Studying relationships between environment and malaria incidence in Camopi (French Guiana) through the objective selection of buffer-based landscape characterisations. Int J Health Geogr. 2011;10(1):65. https://doi.org/10.1186/1476-072X-10-65.

156. Klinkenberg E, van der Hoek W, Amerasinghe FP. A malaria risk analysis in an irrigated area in Sri Lanka. Acta Trop. 2004;89(2):215-25. https:// doi.org/10.1016/j.actatropica.2003.08.007.

157. Austin KF, Bellinger MO, Rana P. Anthropogenic forest loss and malaria prevalence: a comparative examination of the causes and disease consequences of deforestation in developing nations. AIMS Environ Sci. 2017:4(2):217-31. https://doi.org/10.3934/environsci.2017.2.217.

158. Chang MS, Hii J, Buttner P, Mansoor F. Changes in abundance and behaviour of vector mosquitoes induced by land use during the development of an oil palm plantation in Sarawak. Trans R Soc Trop Med Hyg. 1997;91(4):382-6. https://doi.org/10.1016/S0035-9203(97)90248-0.

159. Rubio-Palis Y, Bevilacqua M, Medina DA, Moreno JE, Cárdenas L,

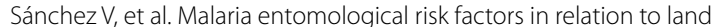
cover in the Lower Caura River Basin. Venezuela Memórias do Instituto Oswaldo Cruz. 2013;108(2):220-8. https://doi.org/10.1590/0074-02761 08022013015

160. de Oliveira EC, dos Santos ES, Zeilhofer P, Souza-Santos R, Atanaka-Santos M. Spatial patterns of malaria in a land reform colonization project, Juruena municipality, Mato Grosso, Brazil. Malar J. 2011;10(1):177. https://doi.org/10.1186/1475-2875-10-177.

161. Chand G, Chaudhary NK, Soan V, Kaushal LS, Sharma RK, Singh N. Transmission dynamics \& epidemiology of malaria in two tribal districts in Madhya Pradesh, India. Indian J Med Res. 2015;141(5):556. https://doi. org/10.4103/0971-5916.159513.

162. Durnez L, Mao S, Denis L, Roelants P, Sochantha T, Coosemans M. Outdoor malaria transmission in forested villages of Cambodia. Malar J. 2013;12(1):329. https://doi.org/10.1186/1475-2875-12-329.

163. Rakotomanana F, Ratovonjato J, Randremanana RV, Randrianasolo L, Raherinjafy R, Rudant JP, Richard V. Geographical and environmental approaches to urban malaria in Antananarivo (Madagascar). BMC Infect Dis. 2010;10(1):173. https://doi.org/10.1186/1471-2334-10-173. 
164. Maheu-Giroux M, Casapía M, Soto-Calle VE, Ford LB, Buckeridge DL, Coomes OT, Gyorkos TW. Risk of malaria transmission from fish ponds in the Peruvian Amazon. Acta Trop. 2010;115(1-2):112-8. https://doi.org/ 10.1016/j.actatropica.2010.02.011.

165. Barrera R, Grillet ME, Rangel Y, Berti J, Aché A. Temporal and spatial patterns of malaria reinfection in northeastern Venezuela. Am J Trop Med Hyg. 1999;61 (5):784-90. https://doi.org/10.4269/ajtmh.1999.61.784.

166. Nixon CP, Nixon CE, Arsyad DS, Chand K, Yudhaputri FA, Sumarto W, et al. Distance to Anopheles sundaicus larval habitats dominant among risk factors for parasitemia in meso-endemic Southwest Sumba. Indonesia Pathogens Global Health. 2014;108(8):369-80. https://doi.org/10. 1179/2047773214Y.0000000167.

167. Monteiro de Barros FS, Honório NA, Arruda ME. Temporal and spatial distribution of malaria within an agricultural settlement of the Brazilian Amazon. JVect Ecol. 2011;36(1):159-69. https://doi.org/10.1111/j.19487134.2011.00153.x.

168. Jaleta KT, Hill SR, Seyoum E, Balkew M, Gebre-Michael T, Ignell R, Tekie $\mathrm{H}$. Agro-ecosystems impact malaria prevalence: large-scale irrigation drives vector population in western Ethiopia. Malar J. 2013;12(1):350. https://doi.org/10.1186/1475-2875-12-350.

169. Ijumba JN, Shenton FC, Clarke SE, Mosha FW, Lindsay SW. Irrigated crop production is associated with less malaria than traditional agricultural practices in Tanzania. Trans R Soc Trop Med Hyg. 2002;96(5):476-80. https://doi.org/10.1016/S0035-9203(02)90408-6.

170. Ijumba JN, Mosha FW, Lindsay SW. Malaria transmission risk variations derived from different agricultural practices in an irrigated area of northern Tanzania. Med Vet Entomol. 2002;16(1):28-38. https://doi.org/ 10.1046/j.0269-283x.2002.00337.x.

171. Mboera LE, Senkoro KP, Mayala BK, Rumisha SF, Rwegoshora RT, Mlozi MR, Shayo ES. Spatio-temporal variation in malaria transmission intensity in five agro-ecosystems in Mvomero district. Tanzania. 2010. https:// doi.org/10.4081/gh.2010.198.

172. Haque U, Hashizume M, Glass GE, Dewan AM, Overgaard HJ, Yamamoto T. The role of climate variability in the spread of malaria in Bangladeshi highlands. PLoS ONE. 2010;5(12):e14341. https://doi.org/10.1371/journ al.pone.0014341.

173. Fuller DO, Alimi T, Herrera S, Beier JC, Quiñones ML. Spatial association between malaria vector species richness and malaria in Colombia. Acta Trop. 2016;158:197-200. https://doi.org/10.1016/j.actatropica.2016.03. 008.

174. Roux O, Vantaux A, Roche B, Yameogo KB, Dabiré KR, Diabaté A, et al. Evidence for carry-over effects of predator exposure on pathogen transmission potential. Proc R Soc B Biol Sci. 1821;2015(282):20152430. https://doi.org/10.1098/rspb.2015.2430.

175. Stauffer JR, Madsen H, McKaye K, Konings A, Bloch P, Ferreri CP, Makaula P. Schistosomiasis in Lake Malawi: relationship of fish and intermediate host density to prevalence of human infection. EcoHealth. 2006;3(1):22-7. https://doi.org/10.1007/s10393-005-0007-3.

176. Diakité NR, N'zi KG, Ouattara M, Coulibaly JT, Saric J, Yao PK, et al. Association of riverine prawns and intermediate host snails and correlation with human schistosomiasis in two river systems in south-eastern Côte d'Ivoire. Parasitology. 2018;145(13):1792-800. https://doi.org/10.1017/ S003118201800135X

177. Stensgaard AS, Kristensen TK, Jørgensen A, Kabatereine NB, Rahbek C. Associations between patterns of human intestinal schistosomiasis and snail and mammal species richness in Uganda: can we detect a decoy effect?. Front Biogeogr. 2016. https://doi.org/10.21425/F58321748

178. Hu Y, Xia C, Li S, Ward MP, Luo C, Gao F, et al. Assessing environmental factors associated with regional schistosomiasis prevalence in Anhui Province, Peoples' Republic of China using a geographical detector method. Infect Dis Poverty. 2017;6(1):87. https://doi.org/10.1186/ s40249-017-0299-x.

179. Simoonga C, Kazembe LN, Kristensen TK, Olsen A, Appleton CC, Mubita P, Mubila L. The epidemiology and small-scale spatial heterogeneity of urinary schistosomiasis in Lusaka province, Zambia. Geospatial Health. 2008; 57-67. https://doi.org/10.4081/gh.2008.232

180. Klumpp RK, Chu KY. Importance of the aquatic weed Ceratophyllum to transmission of Schistosoma haematobium in the Volta Lake, Ghana. Bull World Health Organ. 1980;58(5):791.

181. Sokolow SH, Jones IJ, Jocque M, La D, Cords O, Knight A, et al. Nearly 400 million people are at higher risk of schistosomiasis because dams block the migration of snail-eating river prawns. Philos Trans R Soc B Biol Sci. 2017;372(1722):20160127. https://doi.org/10.1098/rstb.2016. 0127.

182. Chaves LF, Hamer GL, Walker ED, Brown WM, Ruiz MO, Kitron UD. Climatic variability and landscape heterogeneity impact urban mosquito diversity and vector abundance and infection. Ecosphere. 2011;2(6):121. https://doi.org/10.1890/ES11-00088.1.

183. LaBeaud AD, Gorman AM, Koonce J, Kippes C, McLeod J, Lynch J, et al. Rapid GIS-based profiling of West Nile virus transmission: defining environmental factors associated with an urban-suburban outbreak in Northeast Ohio, USA. Geospat Health. 2008;2(2):215. https://doi.org/10. 4081/gh.2008.245.

184. Lockaby G, Noori N, Morse W, Zipperer W, Kalin L, Governo R, et al. Climatic, ecological, and socioeconomic factors associated with West Nile virus incidence in Atlanta, Georgia, USA. J Vector Ecol. 2016;41 (2):23243. https://doi.org/10.1111/jvec.12218.

185. Skaff NK, Cheruvelil KS. Fine-scale wetland features mediate vector and climate-dependent macroscale patterns in human West Nile virus incidence. Landsc Ecol. 2016;31 (7):1615-28. https://doi.org/10.1007/ s10980-016-0346-1.

186. Levine RS, Hedeen DL, Hedeen MW, Hamer GL, Mead DG, Kitron UD. Avian species diversity and transmission of West Nile virus in Atlanta, Georgia. Parasites Vectors. 2017;10(1):62. https://doi.org/10.1186/ s13071-017-1999-6.

187. Gardner AM, Lampman RL, Muturi EJ. Land use patterns and the risk of West Nile virus transmission in central Illinois. Vector-Borne Zoonotic Dis. 2014;14(5):338-45. https://doi.org/10.1089/vbz.2013.1477.

188. Johnson BJ, Munafo K, Shappell L, Tsipoura N, Robson M, Ehrenfeld J, Sukhdeo MV. The roles of mosquito and bird communities on the prevalence of West Nile virus in urban wetland and residential habitats. Urban Ecosyst. 2012;15(3):513-31. https://doi.org/10.1007/ s11252-012-0248-1.

189. Papaspyropoulos GK, Giannakopoulos A, Birtsas P, Tsiodras S, Hutchings $M R$, et al. Use of wild bird surveillance, human case data and GIS spatial analysis for predicting spatial distributions of West Nile virus in Greece. PLoS ONE. 2014;9(5):e96935. https://doi.org/10.1371/journal.pone. 0096935.

190. Mackay AJ, Muturi EJ, Ward MP, Allan BF. Cascade of ecological consequences for West Nile virus transmission when aquatic macrophytes invade stormwater habitats. Ecol Appl. 2016;26(1):219-32. https://doi. org/10.1890/15-0050.

191. Mallya S, Sander B, Roy-Gagnon MH, Taljaard M, Jolly A, Kulkarni MA. Factors associated with human West Nile virus infection in Ontario: a generalized linear mixed modelling approach. BMC Infect Dis. 2018;18(1):141. https://doi.org/10.1186/s12879-018-3052-6.

192. Hamer SA, Lehrer E, Magle SB. Wild birds as sentinels for multiple zoonotic pathogens along an urban to rural gradient in greater Chicago. Illinois Zoonoses Public Health. 2012;59(5):355-64. https://doi. org/10.1111/j.1863-2378.2012.01462.x

193. DeGroote JP, Sugumaran R, Brend SM, Tucker BJ, Bartholomay LC. Landscape, demographic, entomological, and climatic associations with human disease incidence of West Nile virus in the state of lowa, USA. Int J Health Geogr. 2008;7(1):19. https://doi.org/10.1186/1476-072X-7-19.

194. Ezenwa VO, Milheim LE, Coffey MF, Godsey MS, King RJ, Guptill SC. Land cover variation and West Nile virus prevalence: patterns, processes, and implications for disease control. Vector-Borne Zoonotic Dis. 2007;7(2):173-80. https://doi.org/10.1089/vbz.2006.0584.

195. LaDeau SL, Calder CA, Doran PJ, Marra PP. West Nile virus impacts in American crow populations are associated with human land use and climate. Ecol Res 2011; 26(5), 909-916. https://doi.org/10.1007/ s11284-010-0725-z

196. Gibbs SE, Wimberly MC, Madden M, Masour J, Yabsley MJ, Stallknecht DE. Factors affecting the geographic distribution of West Nile virus in Georgia, USA: 2002-2004. Vector-Borne Zoonotic Dis. 2006;6(1):73-82. https://doi.org/10.1089/vbz.2006.6.73.

197. Bradley CA, Gibbs SE, Altizer S. Urban land use predicts West Nile virus exposure in songbirds. Ecol Appl. 2008;18(5):1083-92. https://doi.org/ 10.1890/07-0822.1.

198. Koenig WD, Hochachka WM, Zuckerberg B, Dickinson JL. Ecological determinants of American crow mortality due to West Nile virus during 
its North American sweep. Oecologia. 2010;163(4):903-9. https://doi. org/10.1007/s00442-010-1627-z.

199. Swaddle JP, Calos SE. Increased avian diversity is associated with lower incidence of human West Nile infection: observation of the dilution effect. PLoS ONE. 2008;3(6):e2488.

200. McKenzie VJ, Goulet NE. Bird community composition linked to human West Nile virus cases along the Colorado front range. EcoHealth. 2010;7(4):439-47. https://doi.org/10.1007/s10393-010-0360-8.

201. Loss SR, Hamer GL, Walker ED, Ruiz MO, Goldberg TL, Kitron UD, Brawn JD. Avian host community structure and prevalence of West Nile virus in Chicago. Illinois Oecologia. 2009;159(2):415-24. https://doi.org/10. 1007/s00442-008-1224-6.

202. Ezenwa VO, Godsey MS, King RJ, Guptill SC. Avian diversity and West Nile virus: testing associations between biodiversity and infectious disease risk. Proc R Soc B Biol Sci. 2005;273(1582):109-17. https://doi. org/10.1098/rspb.2005.3284
203. Allan BF, Langerhans RB, Ryberg WA, Landesman WJ, Griffin NW, Katz RS, et al. Ecological correlates of risk and incidence of West Nile virus in the United States. Oecologia. 2009;158(4):699-708. https://doi.org/10.1007/ s00442-008-1169-9.

204. Reisen WK, Barker CM, Carney R, Lothrop HD, Wheeler SS, Wilson JL, et al. Role of corvids in epidemiology of West Nile virus in southern California. J Med Entomol. 2014;43(2):356-67. https://doi.org/10.1093/ jmedent/43.2.356.

\section{Publisher's Note}

Springer Nature remains neutral with regard to jurisdictional claims in published maps and institutional affiliations.
Ready to submit your research? Choose BMC and benefit from:

- fast, convenient online submission

- thorough peer review by experienced researchers in your field

- rapid publication on acceptance

- support for research data, including large and complex data types

- gold Open Access which fosters wider collaboration and increased citations

- maximum visibility for your research: over $100 \mathrm{M}$ website views per year

At BMC, research is always in progress.

Learn more biomedcentral.com/submissions 